\title{
Identifying Persuasive Design Principles and Behavior Change Techniques Supporting End User Values and Needs in eHealth Interventions for Long-Term Weight Loss Maintenance: Qualitative Study
}

Rikke Aune Asbjørnsen ${ }^{1,2,3}$, MSc; Jobke Wentzel ${ }^{1,4}, \mathrm{PhD}$; Mirjam Lien Smedsrød ${ }^{5}$, MSc; Jøran Hjelmesæth ${ }^{6,7}, \mathrm{PhD}$; Matthew M Clark ${ }^{8}$, PhD; Lise Solberg Nes ${ }^{3,8,9^{*}}$, PhD; Julia E W C Van Gemert-Pijnen ${ }^{1,10,11^{*}}$, PhD

${ }^{1}$ Centre for eHealth and Wellbeing Research, Department of Psychology, Health and Technology, University of Twente, Enschede, Netherlands

${ }^{2}$ Research and Innovation Department, Vestfold Hospital Trust, Tønsberg, Norway

${ }^{3}$ Department of Digital Health Research, Division of Medicine, Oslo University Hospital, Oslo, Norway

${ }^{4}$ Research Group IT Innovations in Health Care, Windesheim University of Applied Sciences, Zwolle, Netherlands

${ }^{5}$ Collaborative Care Unit, Sørlandet Hospital Trust, Kristiansand, Norway

${ }^{6}$ Morbid Obesity Center, Vestfold Hospital Trust, Tønsberg, Norway

${ }^{7}$ Department of Endocrinology, Morbid Obesity and Preventive Medicine, Institute of Clinical Medicine, University of Oslo, Oslo, Norway

${ }^{8}$ Department of Psychiatry \& Psychology, Mayo Clinic, College of Medicine \& Science, Rochester, MN, United States

${ }^{9}$ Institute of Clinical Medicine, Faculty of Medicine, University of Oslo, Oslo, Norway

${ }^{10}$ University Medical Center Groningen, Groningen, Netherlands

${ }^{11}$ University of Waterloo, Waterloo, ON, Canada

*these authors contributed equally

\section{Corresponding Author:}

Rikke Aune Asbjørnsen, MSc

Centre for eHealth and Wellbeing Research

Department of Psychology, Health and Technology

University of Twente

De Zul 10

Enschede, $7522 \mathrm{NJ}$

Netherlands

Phone: 31534899111

Email: r.a.asbjornsen@utwente.nl

\section{Abstract}

Background: An increasing number of eHealth interventions aim to support healthy behaviors that facilitate weight loss. However, there is limited evidence of the effectiveness of the interventions and little focus on weight loss maintenance. Knowledge about end user values and needs is essential to create meaningful and effective eHealth interventions, and to identify persuasive system design (PSD) principles and behavior change techniques (BCTs) that may contribute to the behavior change required for successful long-term weight loss maintenance.

Objective: This study aimed to provide insight into the design of eHealth interventions supporting behavior change for long-term weight maintenance. The study sought to identify the values and needs of people with obesity aiming to maintain weight after weight loss, and to identify PSD principles, BCTs, and design requirements that potentially enable an eHealth intervention to meet end user values and needs.

Methods: This study presents the concept of integrating PSD principles and BCTs into the design process of eHealth interventions to meet user values and needs. In this study, individual interviews and focus groups were conducted with people with obesity $(n=23)$ and other key stakeholders $(n=27)$ to explore end user values and needs related to weight loss maintenance. Design thinking methods were applied during the focus group sessions to identify design elements and to explore how eHealth solutions can support the needs to achieve sustainable weight loss maintenance. The PSD model and behavior change taxonomy by Michie were used to identify PSD principles and BCT clusters to meet end user values and needs. 
Results: A total of 8 key end user values were identified, reflecting user needs for weight loss maintenance support: self-management, personalized care, autonomy, feel supported, positive self-image, motivation, happiness, and health. Goals and planning, feedback and monitoring, repetition and substitution, shaping knowledge, social support, identity, and self-belief were some of the BCT clusters identified to address these concepts, together with PSD principles such as personalization, tailoring, self-monitoring, praise, and suggestions.

Conclusions: The process of translating end user values and needs into design elements or features of eHealth technologies is an important part of the design process. To our knowledge, this is the first study to explore how PSD principles and BCTs can be integrated when designing eHealth self-management interventions for long-term weight loss maintenance. End users and other key stakeholders highlighted important factors to be considered in the design of eHealth interventions supporting sustained behavior change. The PSD principles and BCTs identified provide insights and suggestions about design elements and features to include for supporting weight loss maintenance. The findings indicate that a combination of BCTs and PSD principles may be needed in evidence-based eHealth interventions to stimulate motivation and adherence to support healthy behaviors and sustained weight loss maintenance.

Trial Registration: ClinicalTrials.gov NCT04537988; https://clinicaltrials.gov/ct2/show/NCT04537988

(J Med Internet Res 2020;22(11):e22598) doi: 10.2196/22598

\section{KEYWORDS}

eHealth; weight loss maintenance; behavior change; design thinking; digital health interventions; persuasive technology; human-centered design

\section{Introduction}

\section{The Challenges of Weight Loss Maintenance}

Globally, obesity has grown to epidemic proportions and nearly tripled between 1975 and 2016 [1]. In 2016, more than 650 million adults worldwide were obese [1], which led to individual and societal challenges with regard to health, well-being, and economic burden [2-5]. Many people with obesity manage to lose weight, but an alarmingly large percentage of people (3 out of 4) fail to maintain the lost weight over time [6]; therefore, long-term weight maintenance following weight loss is a major concern.

Sustained health behavior change is required to prevent weight regain [7-9], and the chance of success increases when individuals maintain healthy behaviors and weight loss for 2 to 5 years [10,11]. The US National Weight Control Registry [12] and several weight maintenance-related studies provide information about factors [13] associated with successful long-term weight maintenance [8-12]. The identified factors include continued adherence to behavioral strategies such as frequent self-weighing and habitual routines, including high levels of physical activity, healthy diet, eating breakfast regularly, and consistent eating patterns across weekdays and weekends $[8,10,13-20]$.

The challenges that people face when trying to prevent weight regain after weight loss are complex, with several biological, behavioral, cognitive, emotional, social, and environmental factors interacting [16,21]. To address these challenges, novel solutions and emerging technologies, such as eHealth solutions, have the potential to support the self-management and behavior change processes needed for continued weight control [17,21-26]. At present, several eHealth interventions are available to support weight loss [23,27-29]. However, evidence of long-term effects related to weight loss maintenance solutions is limited. Research examining the potential of design for sustained behavior change through eHealth interventions [27] focusing on weight loss maintenance is therefore needed [30,31].

\section{Combining Persuasive and Behavior Change Techniques in eHealth Design}

eHealth interventions and persuasive technologies offer possibilities for improving self-management of health and are increasingly used to support healthy behaviors for improved health and well-being [26,28-32]. Establishing habits for long-term behavior change and weight loss maintenance is challenging and takes time [10,33]. For long-term behavior change, eHealth interventions need to provide effective self-management strategies, support lifestyle change, and promote healthy behaviors. A major challenge to effective eHealth is to integrate motivating and engaging design elements for adherence and continuity of use [23,34,35]. Despite these challenges, such technologies have the potential to empower individuals and transform health care by shifting the focus from cure to prevention and self-management with improved health outcomes [36-38]. This requires not only attention to existing evidence from research and clinical practice but also careful design in collaboration with end users and other stakeholders to develop and implement feasible and sustainable eHealth solutions [36,39-42]. In the design of eHealth interventions, behavior change techniques (BCTs) [43] and persuasive system design (PSD) principles [44] are increasingly applied to design effective behavioral interventions that motivate, engage, and promote healthy lifestyles in support of continued behavior change [45-47]. Behavior change taxonomy by Michie [43] has been systematically developed to meet the need for standardized reporting when designing and evaluating complex behavior change interventions, building on a broad range of BCTs to describe intervention components and content, independent of theory. The PSD model by Oinas-Kukkonen [26] includes a range of PSD principles that can be applied when designing novel and user-friendly eHealth interventions and persuasive technology to support healthy behaviors and behavior change. 
However, the most effective combination of such techniques and principles remains unclear [23,26,36,43,47-55].

The research team of this study had recently conducted a scoping review [23] that identified PSD principles [26] (eg, personalization, self-monitoring, tailoring, praise, suggestions, rewards, and reminders) and BCT clusters [43] (eg, feedback and monitoring, goals and planning, social support, shaping knowledge, associations, and repetition and substitution) applied in eHealth interventions to stimulate motivation, adherence, and weight loss maintenance [23]. Findings from the review suggest different strategies for losing weight than for weight maintenance [23]. Although eHealth interventions, when developed in line with user needs $[36,56,57]$, have the potential to support the difficult behavior change process needed to prevent long-term weight regain [10,21,23,58-60], the scoping review revealed that user involvement in the design and development of such eHealth interventions is lacking [23]. Moreover, there is insufficient knowledge about the most ideal combinations of PSD principles and BCTs to support weight maintenance over time [23]. To create meaningful and effective digital behavior change interventions, it is essential to identify the end user values and needs and the related PSD principles and BCTs during the requirement specification process [23,32,36,39,61]. A holistic and broad stakeholder-driven approach, including key stakeholders, is imperative to design and develop sustainable eHealth interventions that reflect the values and support the goals of the end users [36,39].

\section{Objectives}

The overall aim of this study was to provide insight into the design of eHealth interventions aiming to support behavior change for long-term weight loss maintenance. The goal was to identify values and needs of people with obesity aiming to maintain weight after weight loss (ie, end users) and how these values and needs can be met by PSD principles and BCTs in eHealth intervention design. The following research questions were addressed:
1. What are the values and needs of people with obesity (ie, end users) aiming to maintain weight after initial weight loss, according to key stakeholders (eg, end users and health care providers)?

2. Which PSD principles, BCTs, and design requirements can be identified to meet end user values and needs?

End user values refer to the main drivers of behavior or high-level needs or requirements (eg, improved health and motivation to maintain healthy routines in the long term), indicating the added values of the technology or a solution to support users in reaching their goals (ie, maintaining weight after weight loss) [36,39]. End user needs refer to demands and low-level requirements (ie, low-level needs) that people want to solve to address their problems (eg, realistic goal setting, self-regulation, and coping skills to maintain weight) $[36,39]$. A value can drive several underlying needs $[36,39,62]$.

A key stakeholder was defined as someone central in understanding end user challenges and needs, including possible latent and future needs, and someone that could provide valuable input on how to meet end user needs in eHealth technology design $[36,63]$.

\section{Methods}

The Double Diamond Framework and the Center for eHealth Research and Disease Management Roadmap

This study builds on the innovation and design framework of the Double Diamond [64,65] and the Center for eHealth Research and Disease Management (CeHRes) comprehensive roadmap [36,39] to guide the design and development of an evidence-based eHealth intervention supporting long-term behavior change and weight loss maintenance. Figure 1 presents a combination of the Double Diamond [64] and the CeHRes roadmap [36,39]. 
Figure 1. The Double Diamond [64] and the Center for eHealth Research and Disease Management roadmap [39] combined: a design thinking process for eHealth design and development.

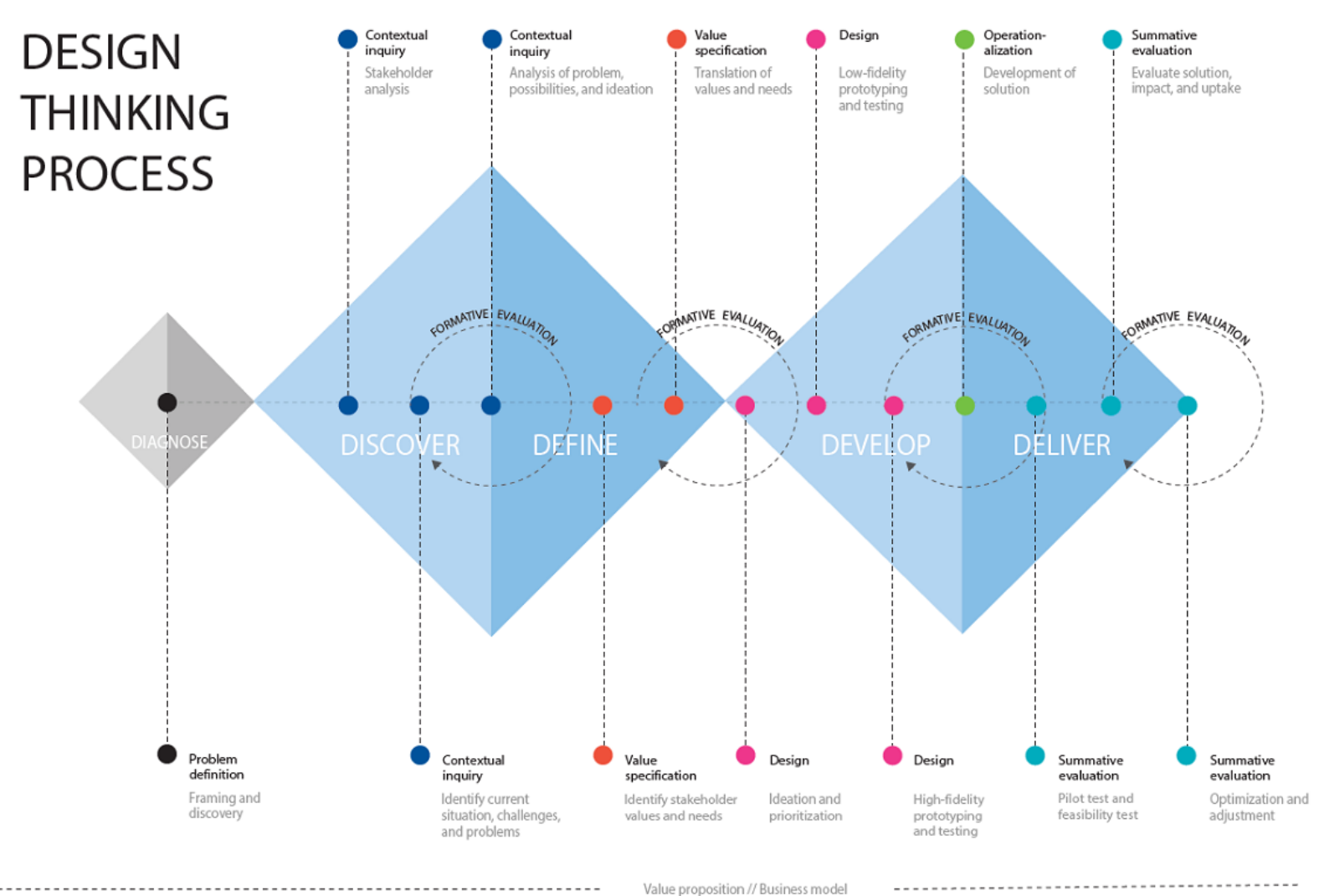

As a first step, a diagnose phase was included [66,67], consisting of the previously performed scoping review [23] and an alignment workshop with the research group (including a user representative) to define the issues at hand (ie, problem definition) and create an initial overview of the stakeholders in the weight loss maintenance conundrum.

The shape of the Double Diamond represents the process of gathering insights (diverging to discover) and translating these insights into ideas or concepts (converging to define) [21,64,65,68-72]. The Double Diamond framework utilizes design thinking methods that can be applied to identify user needs and to find innovative solutions for complex health care challenges [63,70,71,73]. Design thinking explores and elaborates on what is desirable from a user perspective, what is technologically feasible, and what is economically viable [74]. Complementing the design thinking process, the CeHRes roadmap [36,39] was applied as a guideline for holistic development, implementation, and evaluation of eHealth technologies. The CeHRes roadmap consists of the following iterative phases: contextual inquiry, value specification, design, operationalization, and summative evaluation [36,39]. The roadmap integrates concepts of persuasive technology design [26], human-centered design, and business modeling through participatory development with continuous evaluation cycles during the eHealth development and implementation process [39].
This study focuses on the discover and define phase [64] (Figure $1)$, including the contextual inquiry and value specification phases [39]. During the discover phase [64], a stakeholder analysis [63] was executed to identify key stakeholders who could provide insights into the needs, challenges and problems of people aiming to maintain weight after weight loss (ie, end users) [63]. As part of the contextual inquiry, individual interviews and focus group sessions were performed to elicit end user values and needs and to inquire how needs can be met by eHealth technology [36]. During the define phase [64], the values and needs of end users were identified, resulting in value specification [39]. Finally, the PSD model [26], behavior change taxonomy by Michie [43], and the results from the recent scoping review [23] were used to translate values and needs into PSD principles and BCTs [39,75,76].

\section{Key Stakeholder Identification and Recruitment}

\section{Stakeholder Analysis}

To identify key stakeholders, as part of the discover phase, a service design workshop [63] was organized with a multidisciplinary team of stakeholders, consisting of end user representatives (ie, people with obesity aiming to maintain weight after initial weight loss; $n=2$ ), health care personnel (ie, health care providers; $n=5$ ), and project group representatives $(n=3)$. See Figure 2 for study participants, including the participants in the service design workshop. 
Figure 2. Study participants and data collection.

\begin{tabular}{|c|c|c|c|c|}
\hline $\begin{array}{l}\text { Double } \\
\text { Diamond } \\
\text { framework }\end{array}$ & $\begin{array}{l}\text { Research goal and } \\
\text { questions (RQ) }\end{array}$ & Method & End users ${ }^{a}$ & Other key stakeholders \\
\hline $\begin{array}{l}\text { D } \\
\text { I } \\
\text { S } \\
\text { C } \\
\text { O } \\
\text { V } \\
\text { E } \\
\text { R }\end{array}$ & $\begin{array}{l}\text { Identifying key } \\
\text { stakeholders } \\
\text { (to answer in RQ1) }\end{array}$ & $\begin{array}{l}\text { Service } \\
\text { design } \\
\text { workshop }\end{array}$ & End user representative $(n=2)$ & $\begin{array}{r}\text { eHealth researcher }(n=1) \\
\text { Clinical health psychologist }(n=1) \\
\text { eHealth content developer }(n=1) \\
\text { Obesity experts (i.e., physician, } \\
\text { clinical nutritionist, nurse, and } \\
\text { behavioral scientist) }(n=5)\end{array}$ \\
\hline & $\begin{array}{l}\text { Identifying values \& } \\
\text { needs of primary } \\
\text { end-users } \\
\text { (to answer RQ1) }\end{array}$ & $\begin{array}{l}\text { Individual } \\
\text { interviews }\end{array}$ & $\begin{array}{r}\text { End users }(n=10) \\
\text { Patient organization/ } \\
\text { end user representative }(n=1)\end{array}$ & $\begin{array}{r}\text { Primary health care providers }^{\mathrm{b}}(\mathrm{n}=7) \\
\text { Secondary health care providers } \\
\text { (Obesity specialist centers) }(n=4) \\
\text { Private sector }(n=1) \\
\text { Policy level }(n=1)\end{array}$ \\
\hline \multirow[t]{2}{*}{$\begin{array}{l}\text { D } \\
\text { E } \\
\text { F } \\
\text { I } \\
N \\
\text { E }\end{array}$} & $\begin{array}{l}\text { Identifying values, } \\
\text { needs \& design } \\
\text { elements to support } \\
\text { weight maintenance } \\
\text { (to answer RQ1 and } \\
\text { RQ2) }\end{array}$ & $\begin{array}{l}\text { Focus group } \\
\text { interviews }\end{array}$ & End users $(n=10)^{c}$ & $\begin{array}{r}\text { Secondary health care providers } \\
\text { (i.e., physician, behavioral therapist, clinical } \\
\text { nutritionists, and exercise physiologist) } \\
\text { (n=6) }\end{array}$ \\
\hline & & Total $\mathrm{N}=50$ & $\mathrm{n}=23$ & $\mathrm{n}=27$ \\
\hline
\end{tabular}

${ }^{a}$ End users: people with obesity aiming to maintain weight after initial weight loss.

bOne interview was performed as a group interview.

'A total of 2 end users (ie, patients) participated in both individual interviews and focus group

The stakeholder identification workshop was led by a service designer and aimed to create a map of key stakeholders [63] to involve in the research and design process. On the basis of the methods from stakeholder theory and service design $[36,63,73,77,78]$, idea generation was facilitated during the workshop by using a large whiteboard stakeholder map as a mind mapping tool [63], generating a preliminary list of potential stakeholders. The initial list of stakeholders was then narrowed to key stakeholders based on group discussions and mutual agreement during the workshop session. The broad and multidisciplinary stakeholder involvement in this study is part of a holistic and human-centered development [36,39,70,73].

\section{Recruitment of End Users and Other Key Stakeholders}

Prospective end users (ie, people with obesity aiming to maintain weight after initial weight loss - the intervention target group) were defined as adults aged 18 years or above, with BMI $\geq 30 \mathrm{~kg} / \mathrm{m}^{2}$ [79] before weight loss, who had recently lost $8 \%$ weight or more (eg, through a low-calorie diet or lifestyle change program), and who were in need of support to prevent weight regain. People who met these criteria and had previously experienced weight loss, which was followed by weight regain and/or weight maintenance, were selected for study participation. Eligible participants also had to have access to the internet and be fluent in the Norwegian language. Recruitment was conducted over several weeks by 3 collaborative leading obesity research and treatment centers in Norway through convenience sampling, that is, people meeting the inclusion criteria were invited to participate in the study by their health care provider when undergoing treatment or during outpatient follow-up visits. Potential study participants (ie, prospective end users) received written and oral study information, and were invited to participate in individual interviews and focus groups at local hospitals and research centers (Figure 2). If interested, the potential participants were contacted by the research team, provided with an appointment time, and informed that they would receive a gift certificate (approximate value US \$30) as compensation for time spent or of potential costs (eg, transport and parking). Representatives of other key stakeholders identified during the stakeholder analysis (eg, health care providers) were contacted based on convenience sampling and invited to participate in individual interviews and focus groups through the collaborating health care institutions. See Figure 2 for details.

\section{Ethical Approval and Informed Consent}

This study was approved by the Hospital Privacy and Security Protection Committee (institutional review board, approval number: 2017/12702) at Oslo University Hospital (OUH) in Norway, one of the largest medical centers in northern Europe. All participants involved in this study received study information and signed a written informed consent form before participation. 


\section{Identification of End User Values and Needs}

\section{Semistructured Interviews}

As part of the data collection, individual semistructured interviews were performed with prospective end users $(n=11)$ who had recently lost weight and needed support and guidance to prevent weight regain. Other key stakeholders $(n=13)$ were also interviewed to capture a broad perspective and understanding of end user challenges, values, and needs to maintain weight after weight loss $[36,73,80]$ (Figure 2). Interviews with end users and other key stakeholders were guided by the overarching research question: What are the values and needs of people with obesity aiming to maintain weight after initial weight loss?

Individual interviews (60-min to 90-min long) were performed and audio recorded by the first and third author (RA: 17/23, $73 \%$; MS: $6 / 23,26 \%$ ). A semistructured interview guide was developed (Multimedia Appendix 1), providing an overview of the themes to explore. These themes included everyday life, behavior, thoughts, feelings, routines, challenges, strategies, values and needs to maintain weight, experiences and preferences related to health apps, activity and nutrition tracker, and weight management technology (eg, apps, health forums, web-based weight management programs, videos, blogs, and wearables).

\section{Focus Groups}

To further explore and validate the everyday needs of end users and elaborate on engaging and motivating design elements that could potentially support weight maintenance in eHealth design, 3 focus group sessions were held [80-82]. In 2 focus groups, 10 end users $(n=10)$ participated, 5 in each group. In the third focus group, other key stakeholders (ie, health care personnel) participated $(n=6)[81,82]$ (Figure 2). The focus groups lasted approximately 2.5 hours and were facilitated by a service designer and the first author (RA). A digital designer and a Scrum (ie, Agile project management methodology or framework) product owner also participated in the focus groups. The focus group sessions had an explorative and creative character, applying participatory and ideation methods from design thinking [73]. All 3 focus groups were given the following assignment and topics to discuss.

First, a "What is your favorite app?" assignment was performed, where participants described and/or suggested their own apps. The assignment was performed to stimulate creativity and to create trust and social connections within the group. During the assignment, positive and negative aspects of the apps were elaborated on employing brainstorming techniques. The following topics were then explored to provide input for the main research questions:

- What do you/end users need to maintain weight?
- Which design elements can help you/end users to maintain weight?

Sticky notes and a large whiteboard were used to discuss these topics (ie, open-ended questions) with the focus group participants, eliciting potential unmet user needs. This technique was used to create an image of the diversity of user needs [73]. A dynamic and informal discussion, where focus group participants could instantly react to each other's suggestions, provided the researchers with a broad impression of the topics [81].

To identify engaging and motivating design elements, feature cards were applied based on design methods and principles from open card sorting (although applied in a less traditional way than card sorting tasks for information architecture; Multimedia Appendix 2) [83-87]. The cards contained PSD principles and BCTs identified in the previously mentioned scoping review [23]. Additional design elements were included to explore other potentially engaging elements supporting behavior change and to facilitate the creative process related to users' requirements, preferences, and ideas to meet their needs [23,86-90]. These elements include metaphors (eg, when a target is reached, a flower grows in a garden), avatars (eg, a virtual or digital person based on oneself), and gamification elements (eg, points and trophies).

The participants could also choose to develop their own cards with motivational elements through sketching or writing, as some cards had no content (ie, were blank). Examples of how the design elements could be used in app design were presented during the introduction. The focus group participants could choose and sort the cards they identified as useful (ie, to motivate and support weight maintenance) and then share their results in an open group discussion. Participants sorted the selected cards into groups of must have, nice to have, and not needed.

\section{Translation of Values and Needs Into PSD Principles, BCTs, and Design Requirements}

The requirement elicitation methods (ie, individual interviews, focus groups) aimed to capture the user perception of what end users need and how the design of an eHealth technology should be [36]. A total of 3 researchers (RA, MS, and JW) participated in the analysis and validation process of values and needs before translating these into PSD principles, BCTs, and high-level requirements for the design and development of an eHealth weight loss maintenance intervention [91] (Multimedia Appendix 3) [76]. Figure 3 illustrates the steps used when translating end user values and needs into PSD principles, BCT clusters, and high-level design requirements. The presented methods provided input for the main research question: Which $P S D$ principles, $B C T$, and design requirements can be identified to meet the end user' values and needs? 
Figure 3. Value identification and translation of identified values and needs into persuasive system designs, behavior change techniques, and high-level requirements. BCT: behavior change technique; PSD: persuasive system design.

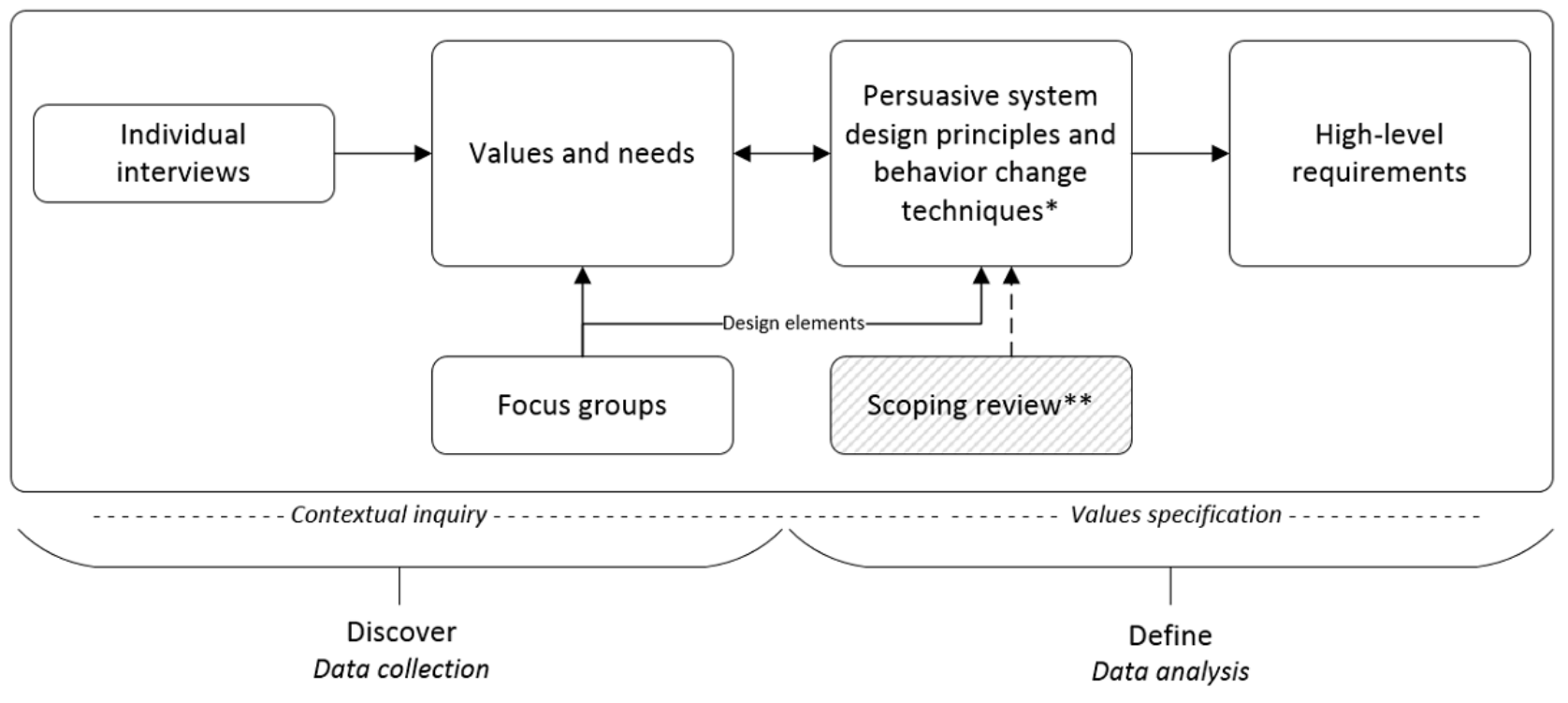

*Identification of PSD principles and BCTs based on the PSD-model and Michie's taxonomy

**Findings from literature review

\section{Data Analysis}

\section{Semistructured Interviews}

As part of the define phase, verbatim transcription of audio recordings of the anonymized interviews $(n=23)$ were analyzed by the first author (RA). Thematic analysis was applied, inspired by Brown and Clark [92], using NVivo (QSR International) qualitative analysis software. End user needs were identified through in-depth analysis and inductive coding of the data until saturation was reached [92]. A second researcher (MS) analyzed $17 \%(4 / 23)$ of the transcribed interviews for analysis validation. Overall, 2 researchers (RA and MS) participated in all of the coding of the identified needs into value categories (performed independently of each other), and a third researcher (JW) participated in validating $1 / 3$ of the coding. The findings were continuously discussed within the research team during this process (RA, LN, MS, JW, LP, and JH). All steps contributed to the development of a comprehensive understanding of the data and to identify a representative and specific set of end user values and needs, as expressed by the key stakeholders [75,76,93]. Multimedia Appendix 3 presents examples from the analysis process related to the key values.

\section{Focus Groups}

The design elements and related needs identified during the 3 focus group sessions were analyzed, documented, and combined by the first author into one overview in a mind mapping tool (XMind, XMind Ltd) [94]. The findings were discussed with the service designer, digital designer, and the Scrum product owner participating in the focus groups, next to the research team. The identified design elements served as input for the analysis and identification of PSD principles and BCTs to meet end user values and needs (Figure 3 ).

\section{Identifying PSD Principles, BCTs, and Design Requirements}

To identify PSD principles and BCTs, the PSD model by Oinas-Kukkonen [26], behavior change taxonomy by Michie [43], previously conducted scoping review [23], and design elements from the focus group sessions were employed (Figure 3). Through small iterations in the analysis process, needs could be linked to one or more end user values. These could then be linked to possible PSD principles and BCT clusters, leading to the formulation of high-level requirements and suggested design features. The identification analysis was performed by the first author and one of the coauthors (RA and MS). A third coauthor (JW) validated $1 / 3$ of the analysis with regard to inconsistencies and disagreements (randomly selected) and contributed to the requirement development. Data analysis and requirement development were continuously discussed by the research team. This identification process resulted in an overview of PSD principles and BCTs aimed at supporting end user values and needs as well as high-level requirements of an eHealth intervention aiming to support weight loss maintenance. The high-level requirements will allow for innovation during the next steps of the design and development process (Figure 1).

\section{Results}

\section{Key Stakeholders and Demographics}

\section{Key Stakeholders}

The key stakeholders identified were prospective end users (ie, people with obesity aiming to maintain weight after initial weight loss) and health care providers from primary and secondary health care providing health services to the target group. Additional key stakeholders identified were policy makers (ie, from the Norwegian Directorate of eHealth); representatives from a patient organization (ie, the Norwegian Association for People with Obesity); and researchers 
conducting research in behavioral medicine, obesity, and weight loss maintenance with clinical experience. See Figure 4 for a final key stakeholder map. In addition, the multidisciplinary design, software, and content development teams involved in the research project were consulted for expert opinions related to digital design and development (included as indirect stakeholders). Figure 2 presents an overview of key stakeholder involvement in each of the separate research processes in this study $(\mathrm{N}=50)$.

Figure 4. Key stakeholder map.

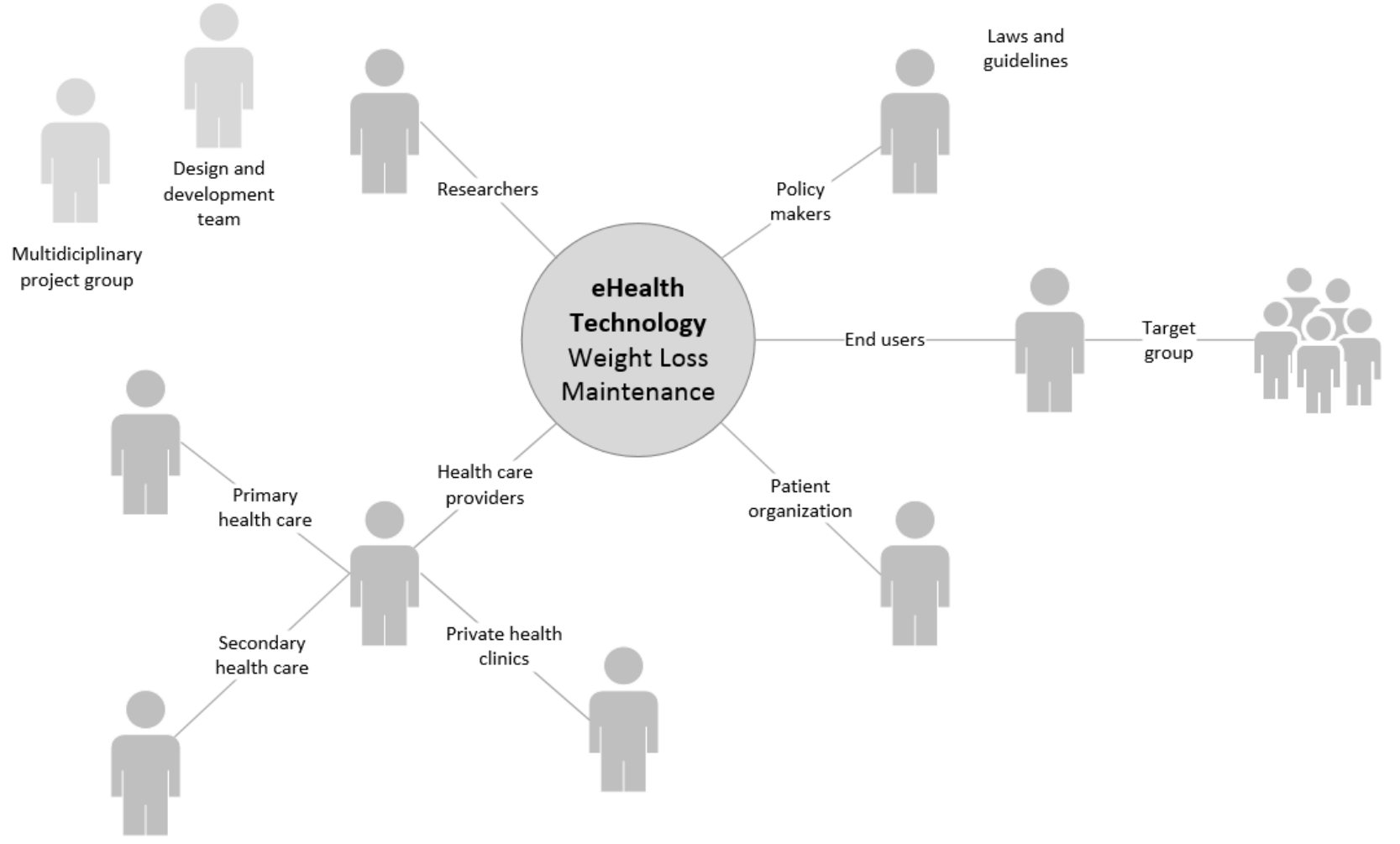

\section{Prospective End Users Involved: General Characteristics}

A total of 21 prospective end users, 67\% (21/50) women, median age 53 years (range 24-70 years), participated in individual interviews and focus groups. As presented in Multimedia Appendix 4, approximately two-thirds of the participating end users reported having had obesity and weight maintenance challenges for most of their life. All end user participants reported having tried various diets (eg, low-calorie and/or very low-calorie diet) and/or conservative treatments (eg, lifestyle programs) to lose weight. They all also described having had several attempts to maintain their weight loss. All participants reported owning a smartphone, tablet, and/or computer and using them on a daily basis for various purposes (eg, social media, news, weather forecasts, financial services, and buying public transport tickets).

\section{Values and Needs of People Aiming to Maintain Weight After Weight Loss}

The results from the individual interviews with end users $(n=11)$ and other key stakeholders (eg, health care personnel, presented in Figure 2; $n=13$ ) revealed that end user needs could be clustered into 8 themes (ie, key values) to maintain weight after weight loss. The 8 key values identified included self-management, personalized care, motivation, feel supported, positive self-image, health, happiness, and autonomy. See Figure 5 for details, including subcategories identified for each of the 8 interconnected values, with some of them overlapping one another. 
Figure 5. Overview of identified key end user values.

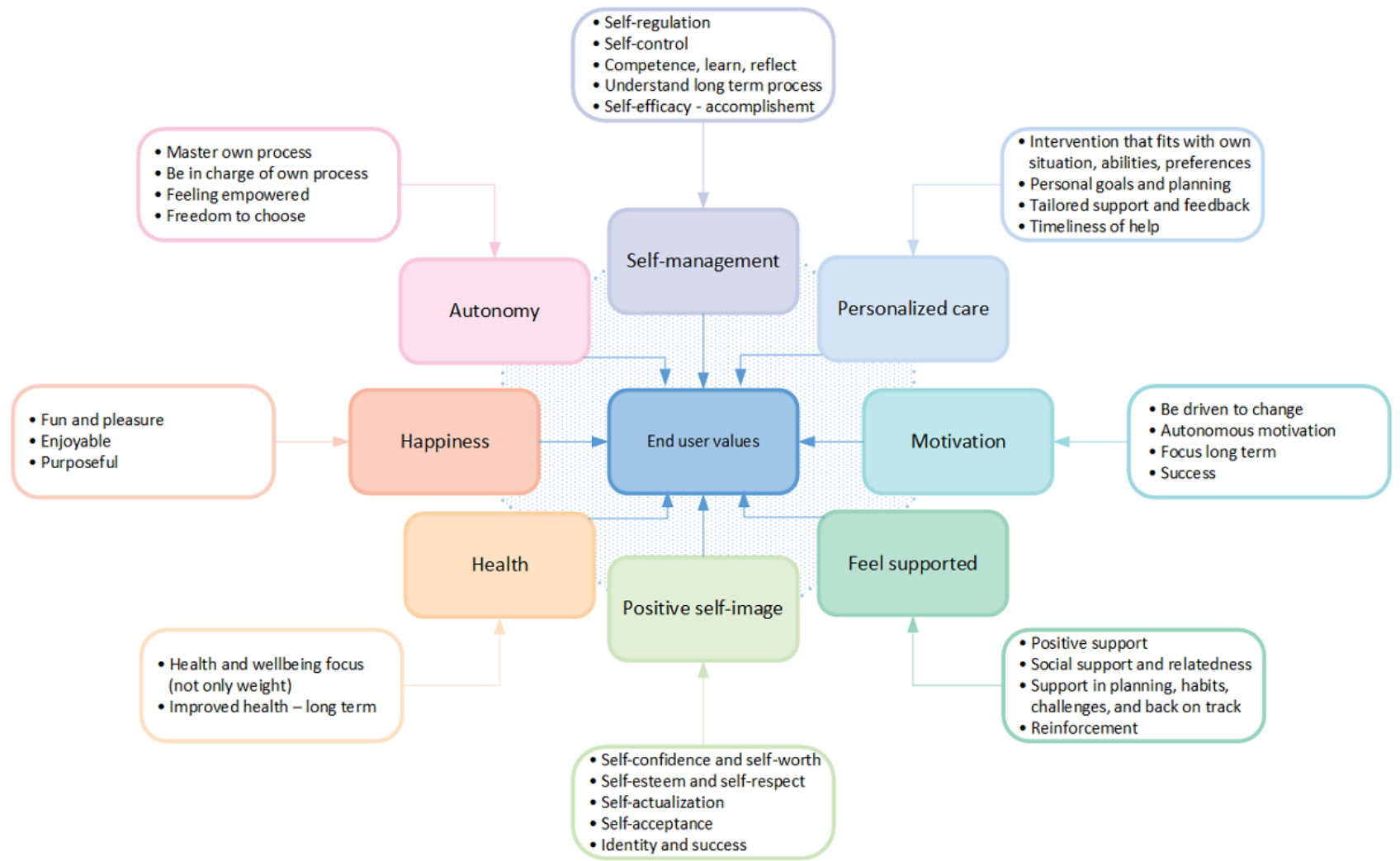

Each specific key value (ie, high-level need or requirement) was generally supported by identified needs. Needs refer to demands and low-level requirements described by end users as aspects to be solved or met to address their weight maintenance problem. In this study, several needs were identified that underlie or support a specific key value (ie, high-level needs). In certain cases, a need could support multiple interrelated key values. For example, the need for positive feedback on good and bad days to keep up with routines and healthy habits could be linked to the value motivation and to the value feel supported. Similarly, the need for personalized self-monitoring could be linked to the value self-management and the value personalized care. Multimedia Appendix 3 provides an overview of examples indicating how low-level end user needs were connected to, and embodied, the key values. The following sections describe the findings related to each of the 8 identified key values.

\section{Key Value: Self-Management}

Self-management or self-regulation was one of the key values highlighted by participants as important to enable sustainable weight maintenance. Many people who struggle to prevent weight regain have difficulties regulating their eating behavior, engaging in physical activities, and establishing new habits:

Many lack competence and skills to do what they actually have learned in practice... [Health care personnel]

In particular, self-regulation strategies and skills to implement into daily routines (eg, planning), dealing with challenges (eg, tempting situations and back on track when weight increases), and strategies for coping with emotional eating and impulse control were highlighted as essential needs within the concept of self-management:
Weight maintenance is all about planning. I would like to have different plans for different situations, a plan A for "normal days and weeks" and a plan B when "crisis occurs," for example cake at work or holidays, to be able to withstand the constant feeling of hunger and tempting situations. [End user]

For self-management, comprehension of one's own process to create awareness and reflection around one's own behavior was considered an essential need by end users and other key stakeholders:

\section{To understand my own behavior and choices is really important. I can reflect and become aware of my own behavior. [End user]}

Help to identify automated behavioral patterns and unhealthy behaviors (eg, eating unhealthy food), self-monitoring of weight and healthy habit support is of essence to understand and regulate behavior.. [Health care personnel]

During the self-management process, the experiences of accomplishment, mastery, and success were deemed especially important to be able to "keep up" over time:

I try to focus on what I actually have reached so far. Sometimes I even try old trousers that are now too big... [End user]

All stakeholders expressed the need for reliable and easily accessible information. As stated by one of the end users, "a lot of information is available for weight loss, but not for weight maintenance." 


\section{Key Value: Personalized Care}

All stakeholders emphasized that needs and requirements differ depending on the person and whether the focus is on weight loss or weight gain prevention. The differences described included aspects such as knowledge, support, and differences in self-management strategies to regulate eating behaviors, negative thoughts, and/or emotions:

\section{People differ, and they experience different challenges over time. [Health care personnel]}

Tailored support to reach goals and establish healthy habits, including small personal steps (ie, subgoals), and to get personal feedback and "information that fits me" (end user) were other needs expressed within the personalized care value:

I would like to choose my own habits, goals and sub-goals to work on, such as reaching a weight target, eating more fruit or walk 6000 steps per day, and to keep track of my own progress. [End user]

\section{Key Value: Motivation}

Finding motivation to keep up with the new habits was highlighted by all stakeholders as an important factor to keep focus and maintain weight. End users stated that being able to identify individual motivators or reasons (ie, intrinsic motivation) for maintaining weight and being able to select goals related to individual purpose were essential for staying motivated over time. Other key stakeholders described being able to focus on important purposes, defined by the end users themselves, could contribute to "strengthening of self-regulation capacity and the autonomous motivation required" for the necessary processes of change:

The real goal is to find out who you want to be and how you want to live your life, and set your own targets, what's important to you? [Health care personnel]

Examples of personal motivators described by end users included having good health, being more social, being able to play with grandchildren, being able to work, fit into normal clothes, and feeling confident. Receiving tailored (social) support and confirmation were also described by end users as crucial to stay motivated during difficult times or when struggling to self-regulate. Other key stakeholders described aspects such as practicing new habits and realistic goal setting, instant reinforcements (ie, rewards, tailored feedback) related to goals and outcomes, reminders of past success, and information about positive versus negative aspects of weight maintenance or regain as being of essence for continued motivation.

\section{Key Value: Feel Supported}

Feeling supported, with positive feedback to keep focus and stay motivated to maintain weight, was seen as crucial by all stakeholders. Several end users mentioned that they lacked support in their social surroundings and/or avoided social settings as much as possible. They described that being able to receive confirmation and (social) support, the feeling of not being alone, and having support on good and bad days or in crisis situations were important needs to be met during weight maintenance:

It feels safe when I am part of something and get follow up. It would be nice to have a technology that supports, especially if the weight goes in the wrong direction, in tempting or crisis situations. [End user]

Other important aspects mentioned by end users included positive reinforcement (eg, praise and self-selected rewards), just-in-time support (eg, tailored feedback and 24/7 availability), and the ability to learn from others by sharing experiences with people in similar situations (eg, social learning, social comparison, cooperation, and social facilitation). These statements were supported by other key stakeholders:
It is really important that the technology motivates and supports me to keep up... [End user]
They need a motivator, somebody cheering on the sideline, to be able to continue with the healthy habits to maintain weight. [Health care personnel]

\section{Key Value: Positive Self-Image}

To feel confident and believe in oneself was mentioned by most stakeholders as being of essence for weight loss maintenance. The participating end users also stated that the focus should be on the whole person, not solely on their weight:

\section{I want to be seen as a person. [End user]}

Several end users and other key stakeholders described that many have low self-confidence after several attempts at weight reduction:

Repetition is the clue and regular confirmation, to not fall back into old routines. If they fall back, they lose their confidence even more. [Health care personnel]

Positive focus on one's strengths and capabilities, the experiences of success, respect for oneself, identity, and self-worth were other areas identified by all end users as important to address to create a more positive self-image and support self-actualization:

\section{I feel confident when I know that I do the right things to stay on track. [End user]}

\section{Key Value: Health}

Several end users described that the cost of maintaining weight after weight loss tends to outweigh the benefits. End users, therefore, stated that they not only want to focus solely on weight but also on positive health effects of a healthier lifestyle and of being less heavy. They indicated that having a good health was one of their main initial motivators to lose weight. Other key stakeholders highlighted aspects such as focusing on short- and long-term health effects of target behavior as important factors to support a feeling of enhanced control and improved health and well-being:

We try to focus on their health and well-being-on the positive effects-some still feel the costs more than the benefits. [Health care personnel] 


\section{Key Value: Happiness}

The end users expressed a preference to bring attention to enjoyable, fun, and positive benefits of healthy behaviors:

Healthy diet and good health should be something fun and nice, not something that gives me a bad conscience and demands a lot of energy. [End user]

To make physical activities more fun, several end users reported using activity trackers or smartphones to monitor activity levels.

Many are highly motivated in the beginning of the weight maintenance phase, until they notice they are still hungry and start to struggle with the same things as in the past. To stay motivated, finding physical activities that bring joy or added purpose and are worth continuing can help. [Health care personnel]

In terms of technology, special attention was also directed toward fun and enjoyable elements to stimulate happiness and positive feelings, so that a healthy lifestyle could be followed to maintain weight:

A technology that gives a fun and meaningful experience...I like to get inspired in a positive and fresh way, maybe with colors, illustrations, symbols and movies. [End user]

The stakeholders also described being able to focus on shortand long-term health rewards of daily habits, through monitoring and rewarding healthy behaviors or targets, as ways to increase pleasure and happiness. One health care personnel said, "A technology that gives joy and a sense of meaning or added value will be used."

Suggestions and information to make healthy eating more attractive and tastier were also described as ways to increase pleasure and happiness. Other key stakeholders also described factors such as making healthy eating more attractive and enjoyable, being able to get information on the health benefits of being active, and to see body composition improve as important factors for gaining insight.

\section{Key Value: Autonomy}

Many end users described the freedom to choose and be in charge as essential aspects to independently master their own behavior change process. They stated that mastery could be reached by having knowledge, abilities, and skills to achieve a healthy lifestyle and continue to do so. The end users also expressed that having customized plans (eg, for weekdays, weekends, holidays) would help induce a feeling of free choice, mastery, and control. Other key stakeholders also supported this:

I would like several modules, not dependent on each other...menus to choose from. A personal choice of what to register, which data to share, and when. [End user]

I think the user should be able to choose their own functions and focus...some need more focus on diet, while other need structuring and planning, like a calendar or reminders. [Health care personnel]

All stakeholders described the following factors as important to be able to choose and continue with healthy habits: facilitating a better understanding of the end users' own process and behavior, enhancing the understanding of how the body and mind work, and learning about health and strategies for self-regulation:

It is important to realize that you have a choice. It is not the surroundings that decide what you eat or do. [Health care personnel]

\section{Identified PSD Principles, BCTs, and Design Requirements of an eHealth Weight Loss Maintenance Intervention}

\section{Focus Group Results: Design Elements}

Focus group findings provided an overview of potential design elements that could meet end user needs when aiming to maintain weight after weight loss. See Table 1 for details. The findings indicate that some design elements were considered more important to incorporate in eHealth weight loss maintenance interventions than others. However, most design elements were characterized as must have during focus groups 2 and 3. 
Table 1. Focus group results with identified design elements.

\begin{tabular}{|c|c|c|c|}
\hline Design elements (cards) & Focus group 1 (end users) & Focus group 2 (end users) & Focus group 3 (health care personnel) \\
\hline Goal setting & $++^{\mathrm{a}}$ & ++ & ++ \\
\hline Planning & ++ & ++ & ++ \\
\hline Motivating messages & ++ & ++ & ++ \\
\hline Personalization & ++ & ++ & ++ \\
\hline Self-monitoring & ++ & ++ & ++ \\
\hline Visualization & ++ & ++ & ++ \\
\hline Tailoring & ++ & ++ & ++ \\
\hline Feedback & ++ & ++ & ++ \\
\hline Knowledge $^{\mathrm{b}}$ & ++ & ++ & ++ \\
\hline Decision support $^{\mathrm{b}}$ & ++ & ++ & ++ \\
\hline Suggestions & ++ & $+^{c}$ & ++ \\
\hline Rewards & + & ++ & ++ \\
\hline Reminders & + & ++ & ++ \\
\hline Wearables or sensor technology & + & ++ & ++ \\
\hline Practice habits & + & ++ & ++ \\
\hline Rehearse on situations or challenges & + & ++ & ++ \\
\hline Social support: health care personnel & + & ++ & ++ \\
\hline Social support: other users & + & + & ++ \\
\hline Social support: virtual coach & + & $-{ }^{\mathrm{d}}$ & + \\
\hline Gamification elements & - & + & + \\
\hline Metaphors & - & - & - \\
\hline Avatar & - & - & - \\
\hline
\end{tabular}

${ }^{\mathrm{a}}$ Elements characterized as must have.

${ }^{\mathrm{b}}$ Design elements suggested by focus group participants.

${ }^{\mathrm{c}}$ Elements characterized as nice to have.

${ }^{\mathrm{d}}$ Elements characterized as not needed.

Needs identified during open brainstorming in the focus groups the analysis process examining the results, the 8 key values were linked to the design elements. See Table 2 for details. In

were linked to the needs identified. 
Table 2. Focus group results with design elements to support weight maintenance needs.

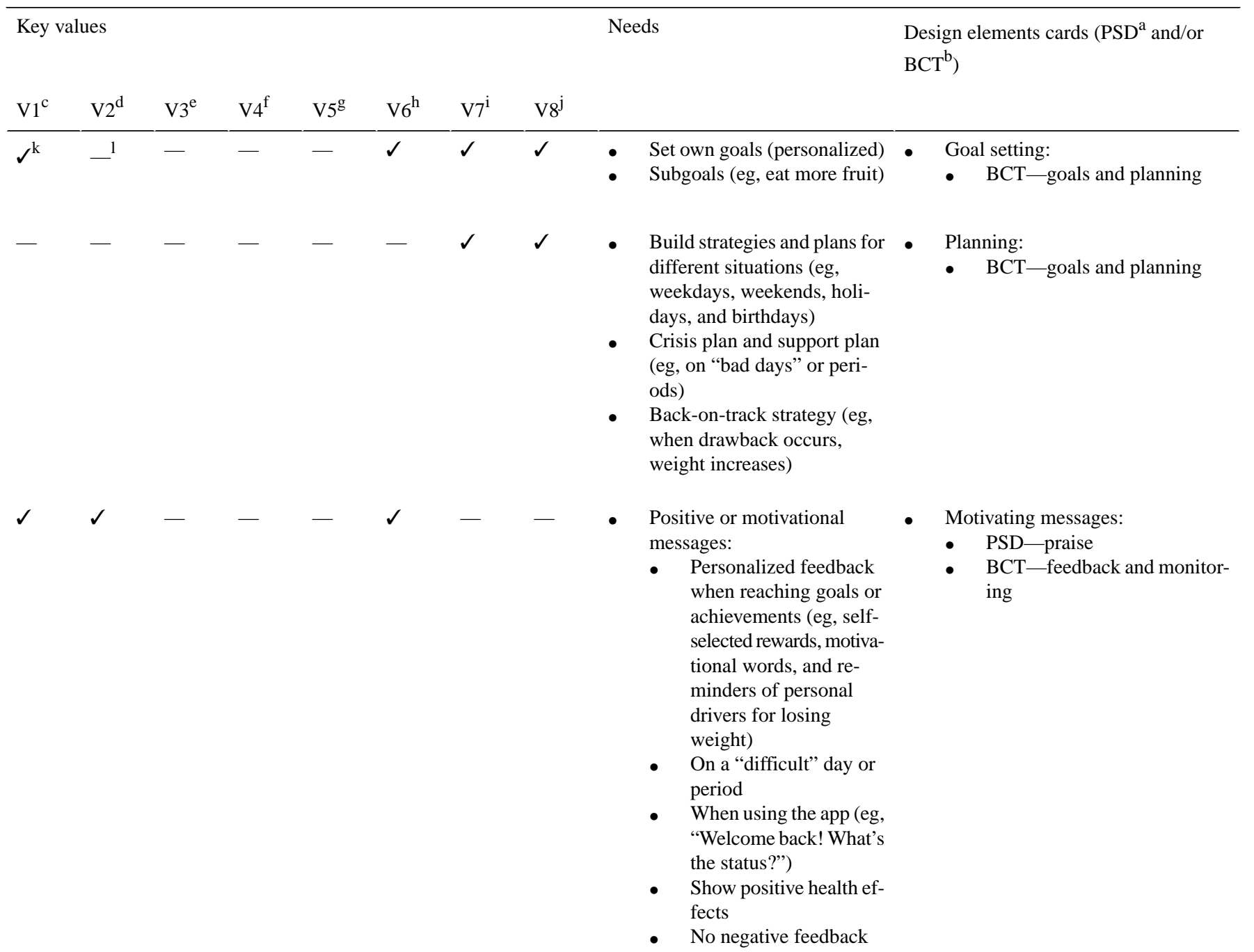

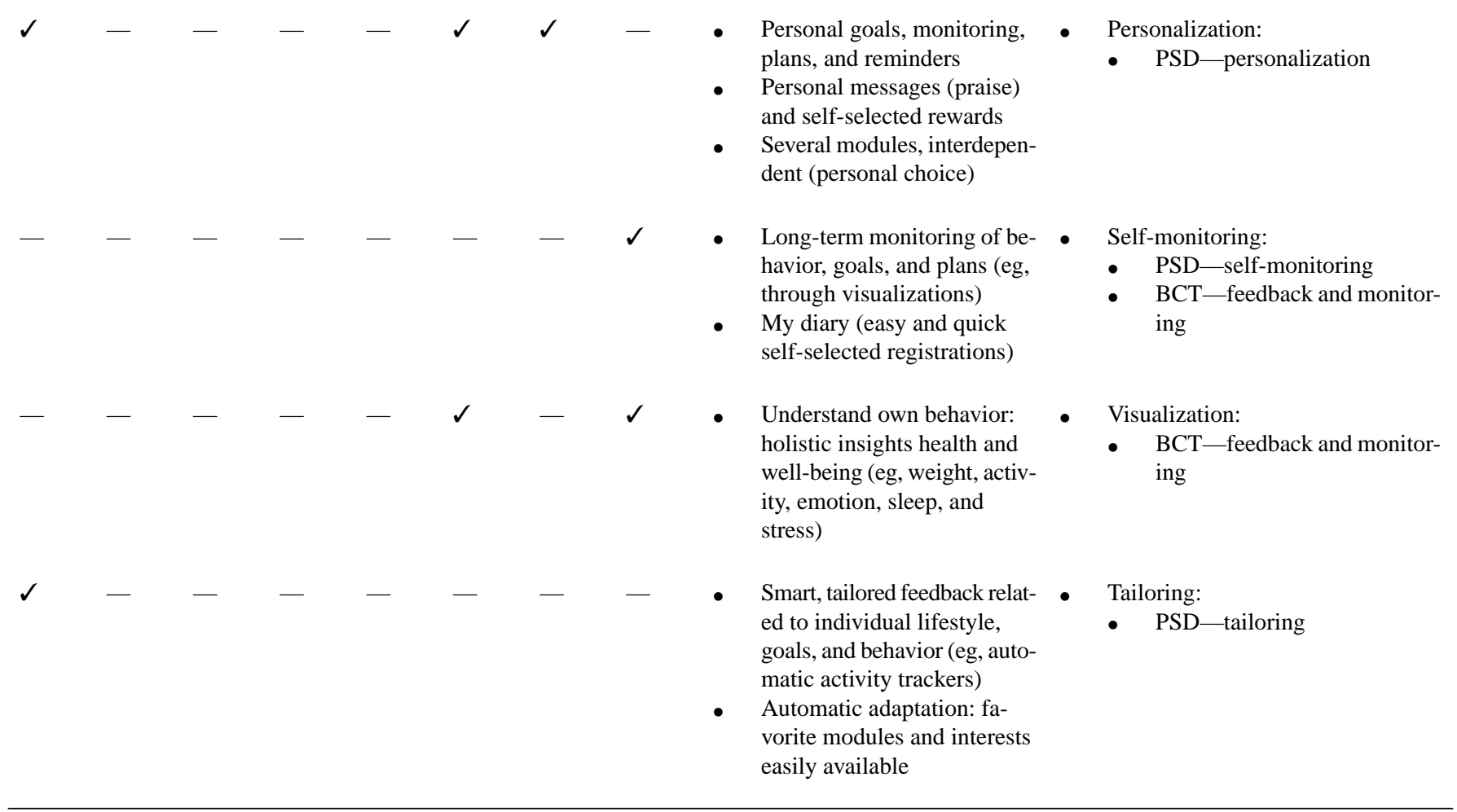




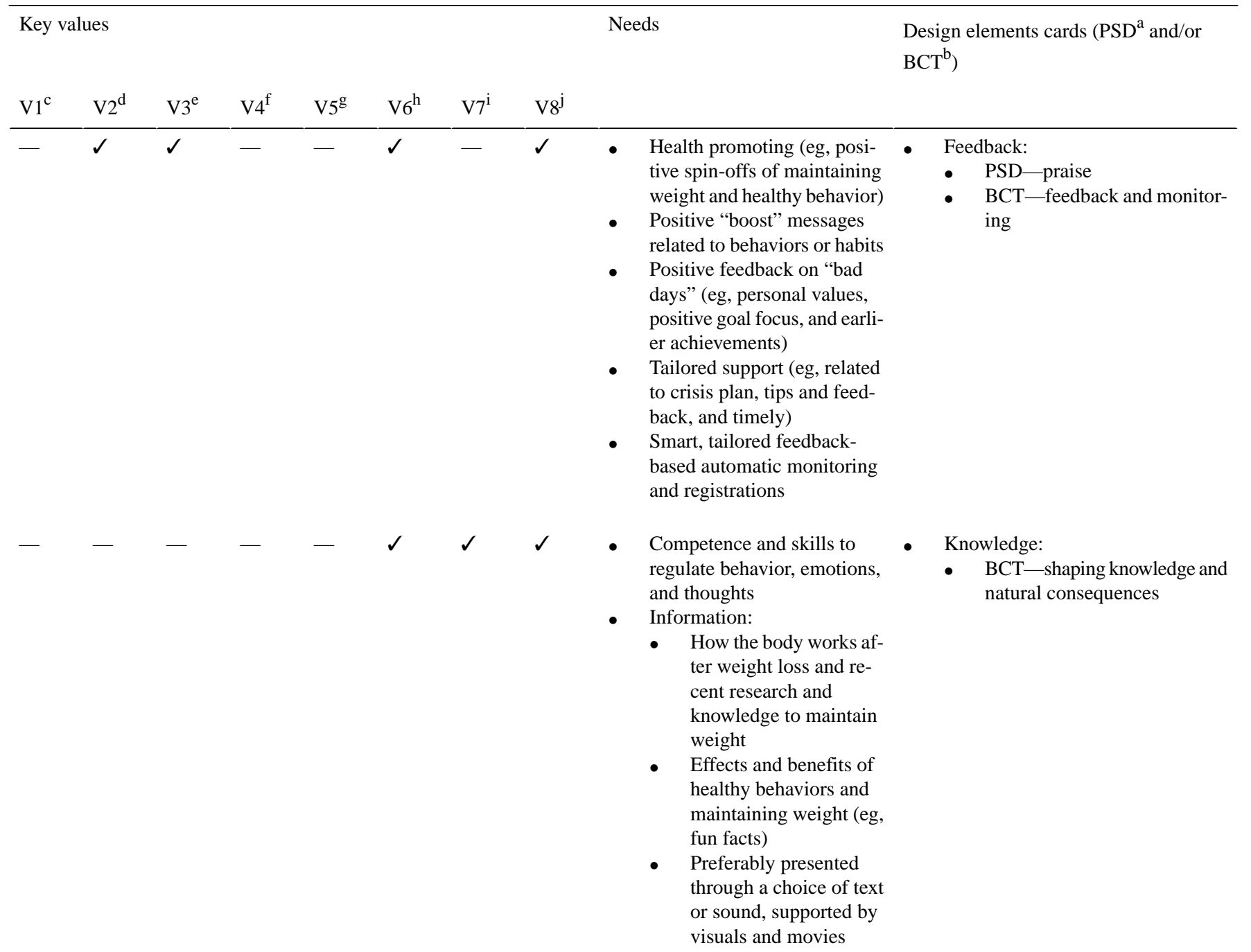

- Reflect on behaviors and decisions

- Support in making healthy choices
- Decision support:

- $\quad$ PSD_reduction and suggestions

- BCT_-antecedents, goals and planning, (eg, action planning), and associations

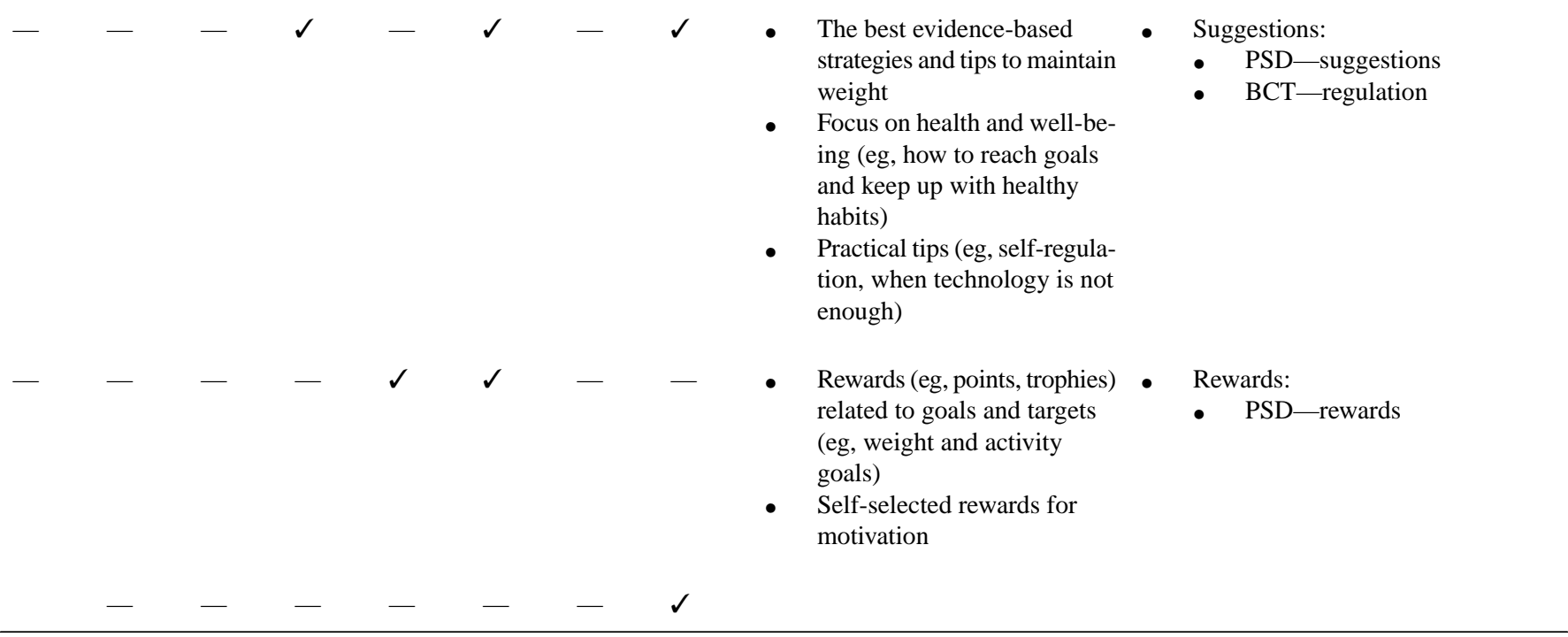




\begin{tabular}{|c|c|c|c|c|c|c|c|c|c|}
\hline \multicolumn{5}{|c|}{ Key values } & \multicolumn{4}{|r|}{ Needs } & \multirow{2}{*}{$\begin{array}{l}\text { Design elements cards }\left(\mathrm{PSD}^{\mathrm{a}} \text { and/or }\right. \\
\left.\mathrm{BCT}^{\mathrm{b}}\right)\end{array}$} \\
\hline $\mathrm{V} 1^{\mathrm{c}}$ & $\mathrm{V} 2^{\mathrm{d}}$ & $V 3^{\mathrm{e}}$ & $\mathrm{V} 4^{\mathrm{f}}$ & $V 5^{\mathrm{g}}$ & $\mathrm{V} 6^{\mathrm{h}}$ & $\mathrm{V} 7^{\mathrm{i}}$ & $\mathrm{V} 8^{\mathrm{j}}$ & & \\
\hline & & & & & & & & $\begin{array}{l}\text { - Reminders: } \\
\text { - My goals, values, and } \\
\text { plan } \\
\text { Healthy habits to main- } \\
\text { tain weight and how the } \\
\text { body works } \\
\text { - When it goes well and } \\
\text { when "off track" (eg, } \\
\text { reminders of past suc- } \\
\text { cesses, trouser that is } \\
\text { too big, before and after } \\
\text { pictures) }\end{array}$ & $\begin{array}{l}\text { - Reminders: } \\
\text { - } \quad \text { PSD—reminders and simula- } \\
\text { tion } \\
\text { BCT—associations (ie, } \\
\text { prompts and cues), self-belief } \\
\text { and identity }\end{array}$ \\
\hline - & - & - & - & $\checkmark$ & $\checkmark$ & - & $\checkmark$ & $\begin{array}{l}\text { Automatic registrations and } \\
\text { automatic behavior trackers } \\
\text { (eg, weight, activity trackers, } \\
\text { wearables, sensors, and smart } \\
\text { devices) } \\
\text { Ease of use, easy monitoring, } \\
\text { and long-term storage of data } \\
\text { Personal contact or helper } \\
\text { (eg, family or friend for moti- } \\
\text { vation and support) }\end{array}$ & $\begin{array}{l}\text { - Wearables or sensor technology: } \\
\text { - } \quad \text { PSD—self-monitoring } \\
\text { - BCT_feedback and monitor- } \\
\text { ing (ie, biofeedback) }\end{array}$ \\
\hline - & - & $\checkmark$ & - & - & - & $\checkmark$ & $\checkmark$ & $\begin{array}{l}\text { - Practice (new) healthy habits } \\
\text { - Keep up with daily routines } \\
\text { and healthy habits in the long } \\
\text { term }\end{array}$ & $\begin{array}{l}\text { - Practice habits: } \\
\text { - } \quad \text { PSD—reduction and rehearsal } \\
\text { - } \quad \text { BCT_repetition and substitu- } \\
\text { tion (ie, habit formation) }\end{array}$ \\
\hline- & - & $\checkmark$ & - & - & - & $\checkmark$ & $\checkmark$ & $\begin{array}{l}\text { - Train and prepare for risk sit- } \\
\text { uations or tempting situations } \\
\text { (eg, "what-if plans," impulse } \\
\text { control, and self-regulation) }\end{array}$ & $\begin{array}{l}\text { - Rehearse on situations or chal- } \\
\text { lenges: } \\
\text { - PSD—rehearsal } \\
\text { - BCT—repetition and substitu- } \\
\text { tion and goals and planning }\end{array}$ \\
\hline - & $\checkmark$ & - & - & - & $\checkmark$ & - & $\checkmark$ & $\begin{array}{l}\text { - Contact with coach or health } \\
\text { care personnel or general } \\
\text { practitioner (eg, when technol- } \\
\text { ogy is not enough) } \\
\text { - Support or personal helper } \\
\text { (eg, family, friend, or other } \\
\text { users or peers through social } \\
\text { forum or chat or inspirational } \\
\text { user stories) to share experi- } \\
\text { ence, learn about health-relat- } \\
\text { ed behaviors from others, and } \\
\text { cooperate }\end{array}$ & $\begin{array}{l}\text { - Social support: } \\
\text { - } \quad \text { PSD—social learning, social } \\
\text { cooperation, and social facili- } \\
\text { tation } \\
\text { - } \quad \begin{array}{l}\text { BCT—social support and } \\
\text { comparison of behavior }\end{array}\end{array}$ \\
\hline - & - & - & - & $\checkmark$ & $\checkmark$ & & - & $\begin{array}{l}\text { Points and trophies when } \\
\text { reaching goals and targets to } \\
\text { keep focus and motivation } \\
\text { - Animated coach for motiva- } \\
\text { tion and joy }\end{array}$ & $\begin{array}{l}\text { - Gamification elements: } \\
\text { - } \quad \text { PSD—rewards } \\
\text { - } \quad \text { BCT—reward and threat }\end{array}$ \\
\hline
\end{tabular}

${ }^{a}$ PSD: persuasive system design.

${ }^{\mathrm{b}} \mathrm{BCT}$ : behavior change technique.

${ }^{\mathrm{c}} \mathrm{V} 1$ : personalized care.

${ }^{\mathrm{d}} \mathrm{V}$ 2: feel supported.

${ }^{\mathrm{e}} \mathrm{V} 3$ : positive self-image. 
${ }^{\mathrm{f}} \mathrm{V} 4$ : health.

${ }^{\mathrm{g}}$ 5: happiness.

${ }^{\mathrm{h}}$ V6: motivation.

${ }^{\mathrm{i}} \mathrm{V7}$ : autonomy.

${ }^{\mathrm{j}} \mathrm{V} 8$ : self-management.

${ }^{\mathrm{k}}$ The value was highlighted by the focus groups based on the needs and related design elements identified.

${ }^{1}$ The value was not highlighted by the focus groups based on the needs and related design elements identified.

The findings indicate that several design elements, supported by PSD principles and BCTs, can be applied to facilitate and motivate short- and long-term behavior changes. Positive feedback, associations (eg, prompts and cues), and rewards (eg, earning points and receive trophies) were identified as motivational elements to inculcate new behavior and for short-term goal setting during the focus group sessions. For long-term behavior change, rewarding strategies linked to, for example, self-selected rewards, identity (eg, reminders of past successes), natural consequences (eg, information about health consequences of performing the behavior), and social support (eg, social cooperation and social learning) were elements identified as potential motivators for sustainable change.

The findings presented in Tables 2 and 3, supported by findings from the previously mentioned scoping review [23], served as input in the analysis to identify PSD principles, BCTs, and requirements of an eHealth intervention to support end user values and needs. 
Table 3. Identified behavior change technique clusters supporting end user values.

\begin{tabular}{|c|c|c|c|c|c|c|c|c|}
\hline \multirow[t]{2}{*}{ Behavior change technique clusters based on behavior change taxonomy by Michie } & \multicolumn{8}{|c|}{ Key values } \\
\hline & $\mathrm{V} 1^{\mathrm{a}}$ & $\mathrm{V} 2^{\mathrm{b}}$ & $\mathrm{V}^{\mathrm{c}}$ & $\mathrm{V} 4^{\mathrm{d}}$ & $\mathrm{V} 5^{\mathrm{e}}$ & $V 6^{\mathrm{f}}$ & $\mathrm{V}^{\mathrm{g}}$ & $\mathrm{V} 8^{\mathrm{h}}$ \\
\hline Scheduled consequences & $-\mathrm{i}$ & - & - & - & - & - & - & - \\
\hline Reward and threat ${ }^{\mathrm{j}}$ & - & - & - & - & $J^{\mathrm{k}}$ & $\checkmark$ & - & - \\
\hline Repetition and substitution ${ }^{1}$ & - & $\checkmark$ & - & - & - & - & $\checkmark$ & $\checkmark$ \\
\hline Antecedents & - & - & - & - & - & $\checkmark$ & $\checkmark$ & $\checkmark$ \\
\hline Associations $\mathrm{j}^{\mathrm{j}, 1}$ & - & - & - & - & - & & $\checkmark$ & $\checkmark$ \\
\hline Covert learning & - & - & - & - & - & $\checkmark$ & - & - \\
\hline Natural consequences ${ }^{\mathrm{m}}$ & - & - & - & $\checkmark$ & - & $\checkmark$ & $\checkmark$ & $\checkmark$ \\
\hline Feedback and monitoring $\mathrm{j}, 1, \mathrm{~m}, \mathrm{n}$ & $\checkmark$ & $\checkmark$ & $\checkmark$ & $\checkmark$ & $\checkmark$ & $\checkmark$ & $\checkmark$ & $\checkmark$ \\
\hline Goals and planning $\mathrm{j}, 1, \mathrm{~m}, \mathrm{n}$ & - & $\checkmark$ & - & - & - & $\checkmark$ & $\checkmark$ & $\checkmark$ \\
\hline Social support ${ }^{\mathrm{j}, 1, \mathrm{~m}, \mathrm{n}}$ & - & $\checkmark$ & $\checkmark$ & - & - & $\checkmark$ & - & $\checkmark$ \\
\hline Comparison of behavior & - & - & - & - & - & - & - & $\checkmark$ \\
\hline Self-belief ${ }^{\mathrm{m}}$ & - & - & $\checkmark$ & & $\checkmark$ & $\checkmark$ & $\checkmark$ & $\checkmark$ \\
\hline Comparison of outcomes & - & - & - & - & - & $\checkmark$ & - & - \\
\hline Identity $^{\mathrm{m}}$ & - & - & $\checkmark$ & - & $\checkmark$ & $\checkmark$ & $\checkmark$ & - \\
\hline Shaping knowledge $e^{1, m, n}$ & $\checkmark$ & - & - & $\checkmark$ & - & - & $\checkmark$ & $\checkmark$ \\
\hline Regulations $^{\mathrm{m}}$ & - & - & $\checkmark$ & - & $\checkmark$ & $\checkmark$ & - & $\checkmark$ \\
\hline
\end{tabular}

${ }^{\mathrm{a}} \mathrm{V} 1$ : personalized care.

${ }^{\mathrm{b}} \mathrm{V} 2$ : feel supported.

${ }^{\mathrm{c}} \mathrm{V}$ : positive self-image.

${ }^{\mathrm{d}} \mathrm{V} 4$ : health.

${ }^{\mathrm{e}} \mathrm{V} 5$ : happiness.

${ }^{\mathrm{f}}$ V6: motivation.

${ }^{\mathrm{g}}$ 7: autonomy.

${ }^{\mathrm{h}}$ V8: self-management.

${ }^{\mathrm{i}}$ Not identified BCTs supporting key values.

${ }^{\mathrm{j}}$ Behavior change techniques (BCTs) mentioned applied to stimulate motivation and/or adherence in weight loss maintenance interventions (for long-term change), identified in the previously performed scoping review [23].

${ }^{\mathrm{k}}$ Identified BCTs supporting the key values.

${ }^{1}$ Most frequently applied behavior change techniques in weight loss maintenance interventions, identified in the previously performed scoping review [23].

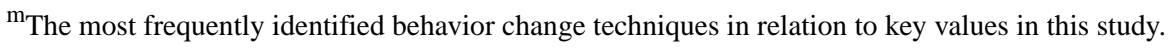

${ }^{\mathrm{n}}$ BCTs included in eHealth interventions that found significant effects for weight loss maintenance, identified in the previously performed scoping review [23].

\section{Identified PSD Principles, BCTs, and Design Requirements of an eHealth Intervention to Support End User Values and Needs}

The end user values and needs identified were mapped using BCT taxonomy by Michie [43] to identify BCT clusters of potential relevance for eHealth interventions supporting long-term weight loss maintenance. See Table 3 for the results of this mapping and analysis.

Of the 16 BCT clusters, 15 could be linked to the identified 8 key values for eHealth weight loss maintenance interventions.
Most BCTs were linked to the key values self-management (11/16), motivation (11/16), and autonomy (9/16). BCT clusters supporting 4 key values or more included natural consequences (eg, information about health and emotional consequences), feedback and monitoring (eg, related to weight and behavior), self-belief (eg, focus on past success and positive self-talk to raise self-confidence), goals and planning (eg, goal setting, action planning, and problem solving, including relapse prevention and coping planning of risks for weight regain), identity (eg, focus on personal strengths or purpose for behavior change associated with the new behavior), shaping knowledge (eg, advice and strategies related to diet, physical activity, and 
behavior change), regulations (eg, skills to regulate or reduce negative emotions), and social support to maintain healthy behaviors.

As indicated in Table 3, goals and planning, feedback and monitoring, and social support were identified as important for weight loss maintenance support by the analysis of BCTs to meet end user values as well as findings from the previous scoping review [23]. The BCT clusters self-belief, natural consequences, and identity were also highlighted as being of essence to meet end user values. However, in the previous scoping review, these BCT clusters were not recognized as frequently applied techniques [23]. The identified BCT clusters in Table 3 (including the underlying techniques) were considered during the high-level requirements specification to illustrate possible combinations of BCTs and PSD principles. Multimedia Appendix 3 presents examples of the BCTs in relation to values, needs, and high-level requirements.

To map the PSD principles relating to end user values and needs, the PSD model [26] was applied. See Table 4 for details. The findings indicate that most of the identified PSD principles were from the primary task (6/7) and dialog support (6/7) categories of the PSD model [26], followed by the social support (4/7) and credibility support (4/7) categories. 
Table 4. Identified persuasive system design principles supporting end user values.

\begin{tabular}{|c|c|c|c|c|c|c|c|c|}
\hline \multirow[t]{2}{*}{ Persuasive system design principles } & \multicolumn{8}{|c|}{ Key values } \\
\hline & $\mathrm{V} 1^{\mathrm{a}}$ & $\mathrm{V} 2^{\mathrm{b}}$ & $\mathrm{V} 3^{\mathrm{c}}$ & $\mathrm{V} 4^{\mathrm{d}}$ & $\mathrm{V} 5^{\mathrm{e}}$ & $V 6^{\mathrm{f}}$ & $\mathrm{V}^{\mathrm{g}}$ & $\mathrm{V} 8^{\mathrm{h}}$ \\
\hline \multicolumn{9}{|l|}{ Primary task support } \\
\hline Reduction & $\mathcal{J}^{\mathrm{i}}$ & $-\mathrm{j}$ & - & - & - & - & $\checkmark$ & $\checkmark$ \\
\hline Tunneling & - & - & - & - & - & - & - & - \\
\hline Tailoring ${ }^{\mathrm{k}, \mathrm{l}, \mathrm{m}}$ & $\checkmark$ & $\checkmark$ & $\checkmark$ & $\checkmark$ & $\checkmark$ & $\checkmark$ & $\checkmark$ & $\checkmark$ \\
\hline Personalization ${ }^{\mathrm{k}, 1, \mathrm{~m}}$ & $\checkmark$ & $\checkmark$ & $\checkmark$ & $\checkmark$ & $\checkmark$ & $\checkmark$ & $\checkmark$ & $\checkmark$ \\
\hline Self-monitoring $\mathrm{k}^{\mathrm{k}, 1, \mathrm{~m}, \mathrm{n}}$ & $\checkmark$ & - & - & $\checkmark$ & $\checkmark$ & $\checkmark$ & $\checkmark$ & $\checkmark$ \\
\hline Simulation $^{1}$ & $\checkmark$ & - & - & - & - & $\checkmark$ & - & $\checkmark$ \\
\hline Rehearsal & - & $\checkmark$ & - & - & - & - & $\checkmark$ & $\checkmark$ \\
\hline \multicolumn{9}{|l|}{ Dialog support } \\
\hline Praise $e^{k, m}$ & $\checkmark$ & $\checkmark$ & $\checkmark$ & $\checkmark$ & $\checkmark$ & $\checkmark$ & - & $\checkmark$ \\
\hline Rewards $^{\mathrm{m}}$ & $\checkmark$ & - & - & - & $\checkmark$ & $\checkmark$ & - & - \\
\hline Reminders $^{1}$ & $\checkmark$ & - & - & - & - & $\checkmark$ & - & $\checkmark$ \\
\hline Suggestions ${ }^{\mathrm{k}}$ & - & $\checkmark$ & - & $\checkmark$ & - & $\checkmark$ & $\checkmark$ & $\checkmark$ \\
\hline Similarity & - & - & - & - & - & - & - & - \\
\hline Liking & - & - & - & - & $\checkmark$ & - & - & - \\
\hline Social role & - & $\checkmark$ & - & - & - & $\checkmark$ & - & - \\
\hline \multicolumn{9}{|l|}{ System credibility support } \\
\hline Trustworthiness & - & - & - & $\checkmark$ & - & - & - & $\checkmark$ \\
\hline Expertise & - & - & - & $\checkmark$ & - & - & - & - \\
\hline Surface credibility & - & - & - & - & - & - & - & - \\
\hline Real-world feel & - & $\checkmark$ & - & - & - & - & - & - \\
\hline Authority & - & - & - & - & - & - & - & - \\
\hline Third-party endorsements & - & - & - & - & - & - & - & - \\
\hline Verifiability & - & - & - & $\checkmark$ & - & - & - & - \\
\hline \multicolumn{9}{|l|}{ Social support } \\
\hline Social learning & - & - & - & - & - & $\checkmark$ & - & $\checkmark$ \\
\hline Social comparison & - & - & - & - & - & $\checkmark$ & - & $\checkmark$ \\
\hline Normative influence & - & - & - & - & - & - & - & - \\
\hline Social facilitation & - & - & - & - & - & - & - & $\checkmark$ \\
\hline Cooperation & - & $\checkmark$ & - & - & - & - & - & - \\
\hline Competition & - & - & - & - & - & - & - & - \\
\hline Recognition & - & - & - & - & - & - & - & - \\
\hline \multicolumn{9}{|l|}{ Others $^{\text {o }}$} \\
\hline Feedback $^{\mathrm{k}, 1, \mathrm{~m}, \mathrm{n}}$ & $\checkmark$ & $\checkmark$ & $\checkmark$ & $\checkmark$ & $\checkmark$ & $\checkmark$ & - & $\checkmark$ \\
\hline Goal setting ${ }^{\mathrm{k}, \mathrm{l}, \mathrm{m}, \mathrm{n}}$ & $\checkmark$ & - & - & - & - & $\checkmark$ & $\checkmark$ & $\checkmark$ \\
\hline Social support ${ }^{\mathrm{k}, \mathrm{m}, \mathrm{n}}$ & - & $\checkmark$ & $\checkmark$ & - & - & $\checkmark$ & - & $\checkmark$ \\
\hline
\end{tabular}

${ }^{\mathrm{a}} \mathrm{V} 1$ : personalized care.

${ }^{\mathrm{b}} \mathrm{V} 2$ : feel supported.

${ }^{\mathrm{c}} \mathrm{V} 3$ : positive self-image. 
${ }^{\mathrm{d}} \mathrm{V} 4$ : health.

eV5: happiness.

${ }^{\mathrm{V}}$ 6: motivation.

gV7: autonomy.

${ }^{\mathrm{h}}$ V8: self-management.

${ }^{\mathrm{i}}$ Identified PSD principles supporting the key values.

${ }^{\mathrm{j}}$ Not identified PSD principles supporting the key values.

${ }^{\mathrm{k}}$ The most frequently identified persuasive system design principles in relation to key values in this study.

${ }^{1}$ Most frequently applied persuasive system design principles in weight loss maintenance, identified in the previous scoping review [23].

${ }^{\mathrm{m}}$ Persuasive system design principles mentioned applied to stimulate motivation and/or adherence in weight loss maintenance, identified in the previous scoping review [23].

${ }^{\mathrm{n}}$ Persuasive system design principles included in eHealth interventions that found significant effects for weight loss maintenance, identified in the previous scoping review [23].

${ }^{\circ}$ Persuasive principles added from the scoping review[23].

PSD principles supporting 4 or more key values included personalization (eg, of goals, self-selected rewards, and content), tailoring (eg, of feedback and information), praise (eg, positive, motivating feedback to keep up with healthy behavior), self-monitoring (eg, of behavior that supports reaching goals), feedback (eg, tailored in relation to already accomplished goals, outcomes, and behavior), suggestions (eg, about healthy eating habits), goal setting (eg, of outcome and target behavior), and social support (eg, through social learning, social comparison, cooperation, or social facilitation by humans or a virtual coach and/or peers). Multimedia Appendix 3 presents examples of the PSD principles identified and how they can be combined with BCTs when specifying high-level requirements for persuasive eHealth technologies supporting weight loss maintenance.

The key values presented under the Values and Needs of People Aiming to Maintain Weight After Weight Loss section and in Tables 3 and 4 represent the wants of the end users and their reasons for those wants. The identified BCT clusters and PSD principles indicate techniques that can be applied to change behavior to maintain weight. Many of the BCT clusters, including underlying techniques, were identified as important to address long-term behavior change (eg, habit formation). The requirement specification included in Multimedia Appendix 3 shows examples of how BCT clusters, such as repetition and substitution, can be combined with PSD principles such as suggestions and reduction, to support sustained behavior change through eHealth technologies.

\section{Discussion}

\section{Principal Findings}

This study aimed to provide insight into the design of eHealth interventions supporting behavior change for long-term weight loss maintenance. The goal was to identify values and needs of people with obesity aiming at maintaining weight after weight loss, and to identify PSD principles, BCTs, and design requirements that meet these values and needs in eHealth interventions. The results revealed specific interconnected key end user values (ie, main drivers of behavior or high-level requirements) and needs (ie, demands or low-level requirements), and also provided insight into BCT clusters and PSD principles and how they can be combined to support end user needs in eHealth interventions.

\section{End User Values and Needs to Maintain Weight After Weight Loss}

The findings from the semistructured interviews and focus groups with key stakeholders were consistent and complemented each other with respect to the 8 interconnected key values that were identified in this study: self-management, personalized care, motivation, feel supported, positive self-image, health, happiness, and autonomy. The key values (ie, main drivers of behavior or high-level requirements) were each supported by identified needs (ie, demands or low-level requirements), sometimes supporting multiple key values. The identified values were interconnected, rather than strictly separated, and dynamic, as the drivers and individual needs can change during long-term maintenance of lost weight.

The 8 identified key values may drive the need for behavior change that is required to successfully maintain weight over time, and motivation and chance for success may increase as these values are met. This means that in eHealth interventions aiming to facilitate sustainable weight loss maintenance, supporting the identified key values in this study could be of essence.

Several of the overlapping end user values identified in this study are in line with research and theories arguing that most behavior is multi-motivated and that a value-driven and positive approach to health and well-being is required to achieve sustainable behavior change [95-98]. In such a holistic approach, behavior tends not to be determined by one value or specific goal but by several dynamic needs simultaneously $[96,97,99,100]$. Theories about motivation, self-regulation, and social learning [101-104] are likely to be of use in the design of eHealth interventions emphasizing values and needs, as identified in this study. For example, the self-determination theory $[103,105]$ offers a macro theory of human motivation and personality, suggesting that motivation to change is dependent on whether people's needs for competence, autonomy, and social relations or relatedness are met. A such, self-determination theory could potentially act as a framework to support several of the identified values and needs, including the individual needs for knowledge and skills (ie, competence) to self-manage, and individual differences with regard to personality, psychological, and/or motivational profile [103,105-108]. 


\section{PSD Principles, BCT Clusters, and Design Requirements to Meet End User Values and Needs}

Several PSD principles and BCT clusters were identified as potentially promising to meet the identified key end user values. Findings from this study are consistent with the results from the scoping review previously conducted by the research team [23], indicating that goals and planning, feedback and monitoring, and social support should be pursued long term to maintain weight $[22,23,107,109-114]$. However, this study revealed some BCT clusters not previously identified (eg, identity and self-belief) [23] that could be important to maintain long-term weight loss.

The challenge related to weight loss maintenance for people with obesity is evident, as many people struggle to maintain weight and may easily fall back into old habits following weight loss [6]. This can be explained by the nature of habits, as habits are often learned, automatic, and sometimes even unconscious processes formed through repetition [25]. In this study, BCTs within the repetition and substitution clusters (eg, habit formation and habit reversal) were identified. Habit formation can be integrated into eHealth interventions to support the formation of new and lasting habits and might be a missing link in the effort to address the challenges related to weight loss maintenance $[7,10,14,15,22,115-121]$. To adapt to the dynamic changes in individual needs over time and to support contextual changes, personalization and tailoring were identified PSD principles of essence in this study.

Findings from this study point to a combination of several PSD principles and BCTs as a necessity to meet end user values and needs in eHealth weight loss maintenance interventions. Persuasive technologies and application of PSD principles in digital behavioral interventions might be key to support long-term weight loss maintenance, especially when combined with BCTs and behavior change theories [23,47]. However, evidence and guidance on how to combine these strategies are nonexistent [23]. PSD principles can be applied to create engaging, user-friendly, persuasive technologies that can support healthy choices and decisions and may be particularly important in the adoption of new habits (eg, suggestions, reduction, self-monitoring, rewards, and feedback). On the other hand, BCTs seem to be important for sustainable behavior change, and the identified techniques (eg, goals and planning, monitoring and feedback, repetition and substitution, associations, antecedents, regulation of emotions, self-belief, and identity) can be learned and put into daily life, even without technology.

In this study, for some of the key values, only a few supporting BCT clusters and/or PSD principles could be identified. This could indicate that some BCTs or PSD principles have yet to be discovered, possibly because some needs may be future or latent needs. It could also indicate that BCT clusters (eg, covert learning) [43] that are not fully desired through identified end user values or needs, but could none the less be important for the required behavior change, should receive particular attention in technology design and may need to be combined with PSD principles (eg, rehearsal) [26] to support the user and create the aspired impact on behavior change.

\section{Implications for Future Design and Practice}

There are numerous potential advantages of digital health technology. Digital technologies can, for example, overcome time and place barriers, with improved accessibility (24/7 availability) and timely support; enable people to track and aggregate real-time data from sensors and smart devices; and may also support personalized and tailored interventions, depending on user behaviors and needs [122]. To date, however, research examining the design for sustainable behavior change is still sparse [23,123].

If centered around end user needs and priorities, digital self-management support systems have the potential to meet several of the key values identified in this study [104,124-128], which might lead to the long-term behavior change needed to maintain weight. The success of such systems also depends on the incorporation of facilitating factors linked to weight maintenance, including self-regulation strategies (eg, cognitive and emotion regulation, goal setting, effective coping, and problem-solving skills), and increased confidence in own ability to self-regulate [13,104,126-128].

Reversal of established behaviors and habits can be challenging, particularly over time [129,130]. However, applying a combination of the identified BCTs and PSD principles (eg, repetition and substitution, identity, feedback and monitoring, goals and planning, and personalization) in future eHealth interventions, linking healthy habits to self-determined goals and identity (eg, individual purpose, health or life goal), might contribute to sustainable behavior change and long-term weight control [52,105,108,125,129,131-136]. According to end users and other key stakeholders, many experience that it costs more than it benefits to change behaviors for continued weight control after weight loss. As identified in this study, digital technologies that are designed to support personal and autonomous motivation, self-efficacy, self-regulation skills, positive body image, self-selected rewards, and health and well-being (eg, not only weight) could also contribute to long-term weight control and improve the cost-benefit ratio that many people experience while trying to balance behaviors to prevent weight regain [23,103,104,111,125,131,134,137,138].

Although eHealth technologies can contribute to improve health care, support sustainable behaviors promoting health and well-being [139], and increase impact and uptake through personalized and tailored design [36,45,122,140-142], eHealth interventions can only be effective if actually used. This means that persuasive and engaging technologies, as examined in this study, have the potential to support people in engagement and adherence to healthy lifestyles in pursuit of their goal of weight maintenance [30,34].

Behavior change interventions are usually complex, and some studies show how interventions incorporating multiple BCTs, rather than just a few BCTs, tend to have larger effects promoting health behavior change [43,54,143-145]. Digital behavioral obesity interventions that combine PSD principles with behavior change theories have also been shown to produce statistically significant weight loss results more frequently [47]. Specifying one ideal combination of PSD principles and BCTs to support sustainable behavior change and weight control in 
eHealth interventions might not be possible. Varying individual values and needs, which requires a personalized and tailored approach, make specifying an ideal combination at the very least challenging $[15,142,146,147]$. Investigating which PSD principles, BCTs, and content that is most effective for sustained engagement, for whom and in which context, should be a goal for future research developing or examining digital weight loss maintenance interventions [107].

With several biological, behavioral, psychological, social, and environmental factors interacting, the challenges related to obesity and weight loss maintenance are complex and numerous $[16,21]$. In this study as well as in the scoping review previously published by the research team [23], personalization and tailoring, including tailored support and personal feedback, were highlighted as factors of great importance for the success of digital interventions targeting behavior change and weight loss maintenance. Individual differences, including personality and psychological profiles that may impact behavior and behavior change, should also be examined and taken into consideration when designing and tailoring such digital interventions in the future [106]. Tailoring based on individual characteristics (eg, personality, motivational orientation) could be of essence when aiming to create effective technological features supporting behavior change [142]. Cognition, affect, and behavior related to individual context have also been identified as core components of engagement and should be considered in the design and development, including the form of delivery and content, of digital interventions aiming to enhance and sustain engagement and support health behavior change [107,147]. In the development process, this issue could be addressed by identifying a variety of user types (eg, personas) [148], and the combination of applied PSD principles and BCTs may potentially be adjusted or tailored per user type $[142,149]$. Ideally, BCTs and PSD principles applied in eHealth behavior change interventions should allow for flexible interaction and adaptability based on the dynamic and changing individual end user needs over time.

Rapid technology developments have changed the way modern organizations approach innovation to create value for end users and stakeholders [68,69,91,150-152]. This study integrates design thinking with BCTs and PSD principles and can guide co-design processes to identify design elements to meet end user values and needs for behavior change in future interventions $[64,65,153]$. The proposed method used in this study also unlocks and explores current, latent, and future user needs and possible solutions through its iterative and participatory process $[21,39,40,68-72,77,154]$. The key values, BCTs, and PSD principles identified in this study can provide input to future design and development processes of eHealth weight maintenance interventions. Co-design and prioritization of BCTs and PSD principles with key stakeholders, including designers and developers, may further develop and specify eHealth interventions, allowing for functional requirements and physical design to be adapted and optimized during prototype development and user testing [40,73,91,155]. In addition, multidisciplinary design teams and quick experiments during the entire design and development process may increase the chance for the technology design to successfully meet user needs. However, as shown in this study, some values and needs could be conflicting. The findings from this study also suggest that some needs, PSD principles, or BCTs for sustainable behavior change are yet to be discovered $[23,36]$.

\section{Recommendation for Future Design, Research, and Implementation}

Considering the significant individual and public health challenges of obesity and weight maintenance after weight loss, novel, human-centered, and evidence-based solutions aiming to close the gap between weight loss and maintenance of the new weight for long term are needed. First, future design and development of research-based eHealth interventions targeting weight maintenance should aim to investigate how to meet the key values identified in this study and capture expectations and uncovered, or potentially latent, end user needs to support weight maintenance over time [91]. Second, personalization appears to be an important ingredient in successful behavior change. Future research should, therefore, examine the role of personalized and emerging eHealth technologies, supporting the integration of identity-oriented approaches with habit formation and self-regulation strategies to achieve long-term behavior change needed to maintain weight after loss. Third, design elements that facilitate autonomous motivation, create a positive experience and engage users over time, contribute to making healthy behaviors enjoyable, and improve self-efficacy and positive self-image through technology should also be examined [141,147,156].

People, technology, and context are intertwined [39,42,157]. Both services and technologies are shaped through their use, which is why design that allows for interaction and continuous adaptation to user requirements, through personalization and tailoring, is particularly important for adoption and long-term use. To be effective, future solutions aiming to support weight loss maintenance should therefore aim to fit both end user values and needs as well as intervention features and context $[42,158]$. For researchers, designers, and developers concerned with supporting long-term weight loss maintenance, the findings indicate potential PSD principles and BCTs that can be applied in digital design for sustained behavior change to address the identified key values. Future research should therefore investigate and evaluate how to combine the PSD principles and BCTs in the best way to develop effective, persuasive eHealth interventions supporting sustainable behavior change and weight loss maintenance. Evaluation of technology use also has the potential to reveal user profiles and promising PSD principles and BCTs, addressing the complexity of behavior change to meet individual needs to maintain weight over time $[60,76,159]$. The value proposition and technology features of future eHealth interventions can be further explored, prioritized, and specified through co-design, prototyping, and testing with key stakeholders, contributing to the next steps of technology design, development, and implementation.

\section{Strengths and Limitations}

This study had some limitations. First, a few of the participating end users were still aiming to reduce weight, although their initial weight loss goal was achieved at the point of recruitment. However, this was the case for a few participants only, and as 
these participants were also focusing on weight gain prevention, the main results were not considered to be significantly affected. End user needs did differ during weight loss compared with weight maintenance, particularly with regard to dietary monitoring and control (ie, calorie count and registration). In reality, these aspects probably vary and interact. This study therefore likely reflects real-life aspects of weight loss or weight maintenance.

Second, more women than men participated in the study, which may have limited generalizability for the male population. Several other key stakeholders were male, potentially enhancing a representative perspective related to male needs and values when aiming to change behavior and maintain weight after weight loss, with the support of eHealth technology.

Third, not all participating end users had experience with successful long-term weight loss maintenance. Needs following a longer period of weight loss maintenance might be different from the needs following a short-term period. As most end users in this study were recruited within 2 to 3 months following weight loss, this could have influenced the findings in this study with regard to long-term needs. By including end users with positive as well as negative experiences from short- and long-term weight gain prevention, a broad view and understanding of the weight maintenance phenomena could be explored.

Fourth, the participants who volunteered for this study might have been more engaged, motivated, and interested in the use of eHealth technologies than the average weight maintenance key stakeholder. Given the nature of the qualitative methods applied in this study, the findings allow for detailed information about a complex issue. However, more research examining aspects of values and needs to maintain weight loss over time is required to enhance generalizability. Finally, identification of PSD principles and BCT clusters might have been prone to subjectivity by the researchers. However, to prevent subjective interpretation, 3 researchers participated in the validation of identified PSD principles and BCTs to reveal and address inconsistencies in this study.

This study also had several strengths. First, the research and development team were multidisciplinary, with clinical and research expertise within behavioral medicine, obesity, eHealth, and persuasive technology, and included user representatives as well as software developers and designers. Second, the methods applied required high levels of end user and other key stakeholder involvement. Such an approach can be time consuming but might be critical for success when designing and developing eHealth interventions [36]. Third, by applying a variety of qualitative methods and involving various stakeholders [36,75,93], a broad understanding of the issues at hand was achieved, capturing and verifying end user needs from various perspectives (eg, patients, health care personnel, and policy makers). Fourth, the mixed and converging research and design methodologies applied [39,68,72], involving multiple researchers in the data collection and analysis processes, aimed to increase validity and reduce possible researcher bias. Finally, the presentation of values and needs and a thorough description of the analysis process identifying and translating PSD principles and BCTs into high-level requirements aimed at contributing to transparency, understanding, and reproducibility of the findings.

\section{Conclusions}

eHealth interventions have the potential to support the regulation of behaviors and maintenance of weight after weight loss. This study contributes to a better understanding of the values and needs of people aiming to maintain weight after weight loss. The translation of values and needs into design elements or features supported by PSD principles and BCTs could play an important role in the design of future eHealth interventions that support sustained behavior change and long-term weight maintenance. How PSD principles and BCTs can be combined in the best way to facilitate behavior change to achieve long-term weight loss maintenance remains to be determined.

The methods described in this study can guide the design of digital interventions and services supporting behavior change to meet end user values and needs in the future. To the best of our knowledge, this is the first study to present insights and suggestions for a new approach on how to identify and translate end user values and needs into PSD principles and BCTs when designing eHealth self-management interventions for sustained behavior change and weight loss maintenance.

\section{Acknowledgments}

This research was funded by OUH and Vestfold Hospital Trust (VHT) in Norway. This study is part of the larger eCHANGE research project (principal investigator: LN) led by the Department of Digital Health Research at OUH, in collaboration with the Department of Endocrinology, Morbid Obesity and Preventive Medicine at OUH; the Morbid Obesity Center at VHT; the Department of Physical Medicine and Rehabilitation at Sørlandet Hospital (SH); and the Norwegian Association for People with Obesity. Related collaborators were surrounding municipalities and international researchers from the University of Twente, the Netherlands, and the Mayo Clinic, the United States. The authors would especially like to thank the study participants (ie, end users, health care personnel, and other key stakeholders) for participating in this research. The authors would also like to thank all collaborating partners, in particular, Inger Marie Flakstad at VHT, Mette Svendsen at OUH, and Nancy Maria Castle at SH, and their teams for their help with study recruitment and Siri Eggesvik at VHT for contributing to service design expertise and illustration of the design thinking process applied in this study.

\section{Conflicts of Interest}

$\mathrm{MC}$ is a consultant for Roche Diabetes Care GmbH. No other authors have made any disclosures. 


\section{Multimedia Appendix 1}

Interview guide.

[PDF File (Adobe PDF File), 92 KB-Multimedia Appendix 1]

\section{Multimedia Appendix 2}

Design elements of feature cards.

[PDF File (Adobe PDF File), 294 KB-Multimedia Appendix 2]

\section{Multimedia Appendix 3}

Value specification, persuasive system design principles and behavior change techniques identification, and high-level requirements development for eHealth interventions supporting weight loss maintenance.

[PDF File (Adobe PDF File), 156 KB-Multimedia Appendix 3]

\section{Multimedia Appendix 4}

Infographics to visualize the demographics of included end users.

[PDF File (Adobe PDF File), 106 KB-Multimedia Appendix 4]

\section{References}

1. Obesity and Overweight - Key Facts. World Health Organization. 2020. URL: http://www.who.int/news-room/fact-sheets/ detail/obesity-and-overweight [accessed 2020-07-01]

2. Ng M, Fleming T, Robinson M, Thomson B, Graetz N, Margono C, et al. Global, regional, and national prevalence of overweight and obesity in children and adults during 1980-2013: a systematic analysis for the global burden of disease study 2013. Lancet 2014 Aug 30;384(9945):766-781 [FREE Full text] [doi: 10.1016/S0140-6736(14)60460-8] [Medline: 24880830]

3. GBD 2015 Obesity Collaborators, Afshin A, Forouzanfar MH, Reitsma MB, Sur P, Estep K, et al. Health effects of overweight and obesity in 195 countries over 25 years. N Engl J Med 2017 Jul 6;377(1):13-27 [FREE Full text] [doi: 10.1056/NEJMoa1614362] [Medline: 28604169]

4. Wang YC, McPherson K, Marsh T, Gortmaker SL, Brown M. Health and economic burden of the projected obesity trends in the USA and the UK. Lancet 2011 Aug 27;378(9793):815-825. [doi: 10.1016/S0140-6736(11)60814-3] [Medline: 21872750]

5. Lee I, Shiroma EJ, Lobelo F, Puska P, Blair SN, Katzmarzyk PT, Lancet Physical Activity Series Working Group. Effect of physical inactivity on major non-communicable diseases worldwide: an analysis of burden of disease and life expectancy. Lancet 2012 Jul 21;380(9838):219-229 [FREE Full text] [doi: 10.1016/S0140-6736(12)61031-9] [Medline: 22818936]

6. Christiansen T, Bruun JM, Madsen EL, Richelsen B. Weight loss maintenance in severely obese adults after an intensive lifestyle intervention: 2- to 4-year follow-up. Obesity (Silver Spring) 2007 Feb;15(2):413-420 [FREE Full text] [doi: 10.1038/oby.2007.530] [Medline: 17299115]

7. McGuire M, Wing R, Klem M, Hill J. Behavioral strategies of individuals who have maintained long-term weight losses. Obes Res 1999 Jul;7(4):334-341. [doi: 10.1002/j.1550-8528.1999.tb00416.x] [Medline: 10440589]

8. Thomas JG, Bond DS, Phelan S, Hill JO, Wing RR. Weight-loss maintenance for 10 years in the national weight control registry. Am J Prev Med 2014 Jan;46(1):17-23. [doi: 10.1016/j.amepre.2013.08.019] [Medline: 24355667]

9. Paixão C, Dias CM, Jorge R, Carraça EV, Yannakoulia M, de Zwaan M, et al. Successful weight loss maintenance: a systematic review of weight control registries. Obes Rev 2020 May;21(5):e13003. [doi: 10.1111/obr.13003] [Medline: $\underline{32048787]}$

10. Wing R, Phelan S. Long-term weight loss maintenance. Am J Clin Nutr 2005 Jul;82(1 Suppl):222S-225S. [doi: $\underline{10.1093 / a j c n / 82.1 .222 S}$ ] [Medline: 16002825$]$

11. Klem M, Wing R, Lang W, McGuire M, Hill J. Does weight loss maintenance become easier over time? Obes Res 2000 Sep;8(6):438-444 [FREE Full text] [doi: 10.1038/oby.2000.54] [Medline: 11011910]

12. The National Weight Control Registry. 1994. URL: http://www.nwcr.ws [accessed 2020-07-01]

13. McKee H, Ntoumanis N, Smith B. Weight maintenance: self-regulatory factors underpinning success and failure. Psychol Health 2013;28(10):1207-1223. [doi: 10.1080/08870446.2013.799162] [Medline: 23767689]

14. Wyatt H, Grunwald G, Mosca C, Klem M, Wing R, Hill J. Long-term weight loss and breakfast in subjects in the national weight control registry. Obes Res 2002 Feb;10(2):78-82 [FREE Full text] [doi: 10.1038/oby.2002.13] [Medline: 11836452]

15. Look AHEAD Research Group, Wadden TA, West DS, Delahanty L, Jakicic J, Rejeski J, et al. The Look AHEAD study: a description of the lifestyle intervention and the evidence supporting it. Obesity (Silver Spring) 2006 May;14(5):737-752 [FREE Full text] [doi: 10.1038/oby.2006.84] [Medline: 16855180] 
16. Montesi L, El Ghoch M, Brodosi L, Calugi S, Marchesini G, Dalle Grave R. Long-term weight loss maintenance for obesity: a multidisciplinary approach. Diabetes Metab Syndr Obes 2016;9:37-46 [FREE Full text] [doi: 10.2147/DMSO.S89836] [Medline: 27013897]

17. Jensen M, Ryan D, Apovian C, Ard J, Comuzzie A, Donato K, American College of Cardiology/American Heart Association Task Force on Practice Guidelines, Obesity Society. 2013 AHA/ACC/TOS guideline for the management of overweight and obesity in adults: a report of the American College of Cardiology/American Heart Association Task Force on Practice Guidelines and The Obesity Society. Circulation 2014 Jun 24;129(25 Suppl 2):S102-S138 [FREE Full text] [doi: 10.1161/01.cir.0000437739.71477.ee] [Medline: 24222017]

18. Brockmann AN, Eastman A, Ross KM. Frequency and consistency of self-weighing to promote weight-loss maintenance. Obesity (Silver Spring) 2020 Jul;28(7):1215-1218. [doi: 10.1002/oby.22828] [Medline: 32437055]

19. Pedersen S, Sniehotta FF, Sainsbury K, Evans EH, Marques MM, Stubbs RJ, et al. The complexity of self-regulating food intake in weight loss maintenance. A qualitative study among short- and long-term weight loss maintainers. Soc Sci Med 2018 Jul;208:18-24. [doi: 10.1016/j.socscimed.2018.05.016] [Medline: 29753930]

20. Karfopoulou E, Mouliou K, Koutras Y, Yannakoulia M. Behaviours associated with weight loss maintenance and regaining in a Mediterranean population sample. A qualitative study. Clin Obes 2013 Oct;3(5):141-149. [doi: 10.1111/cob.12028] [Medline: 25586629]

21. MacLean PS, Wing RR, Davidson T, Epstein L, Goodpaster B, Hall KD, et al. NIH working group report: innovative research to improve maintenance of weight loss. Obesity (Silver Spring) 2015 Jan;23(1):7-15 [FREE Full text] [doi: 10.1002/oby.20967] [Medline: 25469998]

22. Cleo G, Isenring E, Thomas R, Glasziou P. Could habits hold the key to weight loss maintenance? A narrative review. J Hum Nutr Diet 2017 Oct;30(5):655-664. [doi: 10.1111/jhn.12456] [Medline: 28150402]

23. Asbjørnsen RA, Smedsrød ML, Solberg Nes L, Wentzel J, Varsi C, Hjelmesæth J, et al. Persuasive system design principles and behavior change techniques to stimulate motivation and adherence in electronic health interventions to support weight loss maintenance: scoping review. J Med Internet Res 2019 Jun 21;21(6):e14265 [FREE Full text] [doi: 10.2196/14265] [Medline: 31228174]

24. Smith KS, Graybiel AM. Habit formation. Dialogues Clin Neurosci 2016 Apr;18(1):33-43. [doi: 10.31887/DCNS.2016.18.1/ksmith]

25. Fogg B. Tiny Habits. Boston, Massachusetts, USA: Houghton Mifflin Harcourt; 2015:2015.

26. Oinas-Kukkonen H, Harjumaa M. Persuasive systems design: key issues, process model, and system features. Commun Assoc Info Syst 2009;24:485-500. [doi: 10.17705/1CAIS.02428]

27. Marcolino MS, Oliveira JA, D'Agostino M, Ribeiro AL, Alkmim MB, Novillo-Ortiz D. The impact of mhealth interventions: systematic review of systematic reviews. JMIR Mhealth Uhealth 2018 Jan 17;6(1):e23 [FREE Full text] [doi: 10.2196/mhealth.8873] [Medline: 29343463]

28. Klasnja P, Pratt W. Healthcare in the pocket: mapping the space of mobile-phone health interventions. J Biomed Inform 2012 Feb;45(1):184-198 [FREE Full text] [doi: 10.1016/j.jbi.2011.08.017] [Medline: 21925288]

29. Wang J, Cai C, Padhye N, Orlander P, Zare M. A behavioral lifestyle intervention enhanced with multiple-behavior self-monitoring using mobile and connected tools for underserved individuals with type 2 diabetes and comorbid overweight or obesity: pilot comparative effectiveness trial. JMIR Mhealth Uhealth 2018 Apr 10;6(4):e92 [FREE Full text] [doi: 10.2196/mhealth.4478] [Medline: 29636320]

30. Kelders SM, Kok RN, Ossebaard HC, Van Gemert-Pijnen JE. Persuasive system design does matter: a systematic review of adherence to web-based interventions. J Med Internet Res 2012 Nov 14;14(6):e152 [FREE Full text] [doi: 10.2196/jmir.2104] [Medline: 23151820]

31. Sorgente A, Pietrabissa G, Manzoni GM, Re F, Simpson S, Perona S, et al. Web-based interventions for weight loss or weight loss maintenance in overweight and obese people: a systematic review of systematic reviews. J Med Internet Res 2017 Jun 26;19(6):e229 [FREE Full text] [doi: 10.2196/jmir.6972] [Medline: 28652225]

32. Michie S, Yardley L, West R, Patrick K, Greaves F. Developing and evaluating digital interventions to promote behavior change in health and health care: recommendations resulting from an international workshop. J Med Internet Res 2017 Jun 29;19(6):e232 [FREE Full text] [doi: 10.2196/jmir.7126] [Medline: 28663162]

33. Nilsen P, Roback K, Broström A, Ellström PE. Creatures of habit: accounting for the role of habit in implementation research on clinical behaviour change. Implement Sci 2012 Jun 9;7:53 [FREE Full text] [doi: 10.1186/1748-5908-7-53] [Medline: 22682656]

34. Kelders S, Kip H. Development and Initial Validation of a Scale to Measure Engagement with eHealth Technologies. In: Conference on Human Factors in Computing Systems. 2019 Presented at: CHI'19; May 4-9, 2019; Glasgow, United Kingdom. [doi: 10.1145/3290607.3312917]

35. Sieverink F, Kelders SM, van Gemert-Pijnen JE. Clarifying the concept of adherence to ehealth technology: systematic review on when usage becomes adherence. J Med Internet Res 2017 Dec 6;19(12):e402 [FREE Full text] [doi: 10.2196/jmir.8578] [Medline: 29212630]

36. Gemert-Pijnen JE, Kelders S, Kip H, Sanderman R. eHealth Research, Theory and Development: A Multi-Disciplinary Approach. London, UK: Routledge; 2018. 
37. Héroux M, Watt M, McGuire K, Berardi J. A personalized, multi-platform nutrition, exercise, and lifestyle coaching program: a pilot in women. Internet Interv 2017 Mar; 7:16-22 [ [FREE Full text] [doi: $10.1016 /$ j.invent.2016.12.002] [Medline: $\underline{30135822]}$

38. Arnrich B, Mayora O, Bardram J, Tröster G. Pervasive healthcare. Methods Inf Med 2018 Jan 17;49(1):67-73. [doi: 10.3414/me09-02-0044]

39. van Gemert-Pijnen JE, Nijland N, van Limburg M, Ossebaard HC, Kelders SM, Eysenbach G, et al. A holistic framework to improve the uptake and impact of eHealth technologies. J Med Internet Res 2011 Dec 5;13(4):e111 [FREE Full text] [doi: 10.2196/jmir.1672] [Medline: 22155738]

40. Lentferink A, Polstra L, D'Souza A, Oldenhuis H, Velthuijsen H, van Gemert-Pijnen L. Creating value with eHealth: identification of the value proposition with key stakeholders for the resilience navigator app. BMC Med Inform Decis Mak 2020 Apr 27;20(1):76 [FREE Full text] [doi: 10.1186/s12911-020-1088-1] [Medline: 32340615]

41. Støme LN, Moger T, Kidholm K, Kværner KJ. Early assessment of innovation in a healthcare setting. Int J Technol Assess Health Care 2019 Jan;35(1):17-26. [doi: 10.1017/S0266462318003719] [Medline: 30744712]

42. Cruz-Martínez RR, Wentzel J, Asbjørnsen RA, Noort PD, van Niekerk JM, Sanderman R, et al. Supporting self-management of cardiovascular diseases through remote monitoring technologies: metaethnography review of frameworks, models, and theories used in research and development. J Med Internet Res 2020 May 21;22(5):e16157 [FREE Full text] [doi: 10.2196/16157] [Medline: 32436852]

43. Michie S, Richardson M, Johnston M, Abraham C, Francis J, Hardeman W, et al. The behavior change technique taxonomy (v1) of 93 hierarchically clustered techniques: building an international consensus for the reporting of behavior change interventions. Ann Behav Med 2013 Aug;46(1):81-95. [doi: 10.1007/s12160-013-9486-6] [Medline: 23512568]

44. Oinas-Kukkonen H. Persuasive System Design: state of the art and future directions. In: International Conference on Persuasive Technology. 2009 Presented at: CPT'09; April 4-9, 2009; Claremont, California. [doi: 10.1145/1541948.1541989]

45. Lentferink AJ, Oldenhuis HK, de Groot M, Polstra L, Velthuijsen H, van Gemert-Pijnen JE. Key components in ehealth interventions combining self-tracking and persuasive ecoaching to promote a healthier lifestyle: a scoping review. J Med Internet Res 2017 Aug 1;19(8):e277 [FREE Full text] [doi: 10.2196/jmir.7288] [Medline: 28765103]

46. Kelders SM, van Gemert-Pijnen JE, Werkman A, Seydel ER. Evaluation of a web-based lifestyle coach designed to maintain a healthy bodyweight. J Telemed Telecare 2010;16(1):3-7. [doi: 10.1258/jtt.2009.001003] [Medline: 20086259]

47. Sittig S, McGowan A, Iyengar S. Extensive review of persuasive system design categories and principles: behavioral obesity interventions. J Med Syst 2020 Jun 5;44(7):128. [doi: 10.1007/s10916-020-01591-w] [Medline: 32500161]

48. Fogg BJ. Persuasive technology: using computers to change what we think and do. Ubiquity 2002 Dec;2002(December):2. [doi: $10.1145 / 764008.763957]$

49. Pagoto S, Schneider K, Jojic M, DeBiasse M, Mann D. Evidence-based strategies in weight-loss mobile apps. Am J Prev Med 2013 Nov;45(5):576-582. [doi: 10.1016/j.amepre.2013.04.025] [Medline: 24139770]

50. Brindal E, Hendrie GA, Freyne J. Combining persuasive technology with behavioral theory to support weight maintenance through a mobile phone app: protocol for the motimate app. JMIR Res Protoc 2016 Jan 8;5(1):e5 [FREE Full text] [doi: 10.2196/resprot.4664] [Medline: 26747725]

51. Krukowski RA, Harvey-Berino J, Ashikaga T, Thomas CS, Micco N. Internet-based weight control: the relationship between web features and weight loss. Telemed J E Health 2008 Oct;14(8):775-782 [FREE Full text] [doi: 10.1089/tmj.2007.0132] [Medline: 18954247$]$

52. Hermsen S, Frost J, Renes RJ, Kerkhof P. Using feedback through digital technology to disrupt and change habitual behavior: a critical review of current literature. Comput Hum Behav 2016 Apr;57:61-74. [doi: 10.1016/j.chb.2015.12.023]

53. Direito A, Carraça E, Rawstorn J, Whittaker R, Maddison R. Mhealth technologies to influence physical activity and sedentary behaviors: behavior change techniques, systematic review and meta-analysis of randomized controlled trials. Ann Behav Med 2017 Apr;51(2):226-239. [doi: 10.1007/s12160-016-9846-0] [Medline: 27757789]

54. Schoeppe S, Alley S, Van Lippevelde W, Bray NA, Williams SL, Duncan MJ, et al. Efficacy of interventions that use apps to improve diet, physical activity and sedentary behaviour: a systematic review. Int J Behav Nutr Phys Act 2016 Dec 7;13(1):127 [FREE Full text] [doi: 10.1186/s12966-016-0454-y] [Medline: 27927218]

55. Soltani H, Arden MA, Duxbury AM, Fair FJ. An analysis of behaviour change techniques used in a sample of gestational weight management trials. J Pregnancy 2016;2016:1085916 [FREE Full text] [doi: 10.1155/2016/1085916] [Medline: 27034836]

56. Barello S, Triberti S, Graffigna G, Libreri C, Serino S, Hibbard J, et al. Ehealth for patient engagement: a systematic review. Front Psychol 2015;6:2013 [FREE Full text] [doi: 10.3389/fpsyg.2015.02013] [Medline: 26779108]

57. Hesse BW, Shneiderman B. eHealth research from the user's perspective. Am J Prev Med 2007 May;32(5 Suppl):S97-103 [FREE Full text] [doi: 10.1016/j.amepre.2007.01.019] [Medline: 17466825]

58. Neve M, Morgan P, Jones P, Collins C. Effectiveness of web-based interventions in achieving weight loss and weight loss maintenance in overweight and obese adults: a systematic review with meta-analysis. Obes Rev 2010 Apr;11(4):306-321. [doi: 10.1111/j.1467-789X.2009.00646.x] [Medline: 19754633]

59. Evans EH, Araújo-Soares V, Adamson A, Batterham AM, Brown H, Campbell M, et al. The NULevel trial of a scalable, technology-assisted weight loss maintenance intervention for obese adults after clinically significant weight loss: study 
protocol for a randomised controlled trial. Trials 2015 Sep 22;16:421 [FREE Full text] [doi: 10.1186/s13063-015-0931-7] [Medline: 26395774]

60. Cai X, Qiu S, Luo D, Wang L, Lu Y, Li M. Mobile application interventions and weight loss in type 2 diabetes: a meta-analysis. Obesity (Silver Spring) 2020 Mar;28(3):502-509. [doi: 10.1002/oby.22715] [Medline: 31965748]

61. Kelders SM, van Gemert-Pijnen JE, Werkman A, Nijland N, Seydel ER. Effectiveness of a Web-based intervention aimed at healthy dietary and physical activity behavior: a randomized controlled trial about users and usage. J Med Internet Res 2011 Apr 14;13(2):e32 [FREE Full text] [doi: 10.2196/jmir.1624] [Medline: 21493191]

62. Mooc Ehealth: Combining Psychology, Technology and Health - Ehealth: What Are Values? The Open University. University of Twente. 2016. URL: http://www.futurelearn.com/courses/ehealth [accessed 2020-07-01]

63. Stickdorn MS. This is Service Design Thinking: Basics, Tools, Cases. Amsterdam, Netherlands: Wiley; 2014.

64. The Double Diamond: a Universally Accepted Depiction of the Design Process. British Design Council. 2005. URL: http:/ /www.designcouncil.org.uk/news-opinion/double-diamond-universally-accepted-depiction-design-process [accessed 2020-07-01]

65. What is the Framework for Innovation? Design Council's Evolved Double Diamond. British Design Council. 2019. URL: http://www.designcouncil.org.uk/news-opinion/what-framework-innovation-design-councils-evolved-double-diamond [accessed 2020-07-01]

66. StimuLabs Metode: Trippel Diamant. DOGA. 2020. URL: http://doga.no/aktiviteter/design-og-innovasjon/ innovasjon-i-offentlig-sektor/stimulab/arbeidsmetode/ [accessed 2020-06-22]

67. The Triple Diamond. DOGA. 2020. URL: https://doga.no/en/activities/design-og-innovasjon/ stimulation-programme-for-innovation-and-service-design2/hvordan-apne-for-innovasjon/ [accessed 2020-10-23]

68. Roberts JP, Fisher TR, Trowbridge MJ, Bent C. A design thinking framework for healthcare management and innovation. Healthc (Amst) 2016 Mar;4(1):11-14. [doi: 10.1016/j.hjdsi.2015.12.002] [Medline: 27001093]

69. Kolko J. Design Thinking Comes of Age. Harvard Business Review. 2015. URL: http://hbr.org/2015/09/ design-thinking-comes-of-age [accessed 2020-01-07]

70. Polaine A, Reason B, Løvlie L. Service Design - From Insight to Implementation. New York, USA: Rosenfeld Media; 2013.

71. Ferreira F, Song E, Gomes H, Garcia E, Ferreira L. New mindset in scientific method in the health field: design thinking. Clinics (Sao Paulo) 2015 Dec;70(12):770-772. [doi: 10.6061/clinics/2015(12)01] [Medline: 26735214]

72. Altman M, Huang TT, Breland JY. Design thinking in health care. Prev Chronic Dis 2018 Sep 27;15:E117 [FREE Full text] [doi: $10.5888 /$ pcd15.180128] [Medline: $\underline{30264690}$ ]

73. Stickdorn MS, Schneider J. This Is Service Design Thinking: Basics, Tools, Cases. Hoboken, New Jersey: Wiley; 2012.

74. Brown T. Change by Design: How Design Thinking Transforms Organizations and Inspires Innovation. New York, USA: HarperBusiness; 2009.

75. Patton MQ. Enhancing the quality and credibility of qualitative analysis. Health Serv Res 1999 Dec;34(5 Pt 2):1189-1208 [FREE Full text] [Medline: 10591279]

76. van Velsen L, Wentzel J, van Gemert-Pijnen JE. Designing ehealth that matters via a multidisciplinary requirements development approach. JMIR Res Protoc 2013 Jun 24;2(1):e21 [FREE Full text] [doi: 10.2196/resprot.2547] [Medline: 23796508]

77. van Woezik AF, Braakman-Jansen LM, Kulyk O, Siemons L, van Gemert-Pijnen JE. Tackling wicked problems in infection prevention and control: a guideline for co-creation with stakeholders. Antimicrob Resist Infect Control 2016;5:20 [FREE Full text] [doi: 10.1186/s13756-016-0119-2] [Medline: 27213040]

78. van Limburg AH. Implementing Antibiotic Stewardship: Involving Stakeholders in Ehealth. Enschede, The Netherlands: University of Twente; 2016.

79. What is Overweight and Obesity. World Health Organization. URL: https://www.who.int/health-topics/obesity\#tab=tab 1 [accessed 2020-07-01]

80. Green J, Thorogood N. Qualitative Methods for Health Research. Newbury Park, California: SAGE Publications; 2018.

81. Gubrium JF, Holstein JA. Focus group interviewing. In: Handbook of Interview Research: Context and Method. Thousand Oaks, California, USA: Sage Publications; 2002.

82. Pope C, Mays N. Qualitative Research in Health Care. Hoboken, New Jersey: Blackwell Publishing Ltd; 2006.

83. Morville PR, Rosenfeld L. Information Architecture for the World Wide Web. Newton, Massachusetts, USA: O'Reilly Media; 2007.

84. Wentzel J, van Velsen L, van Limburg M, de Jong N, Karreman J, Hendrix R, et al. Participatory eHealth development to support nurses in antimicrobial stewardship. BMC Med Inform Decis Mak 2014 Jun 5;14:45 [FREE Full text] [doi: 10.1186/1472-6947-14-45] [Medline: 24898694]

85. Simonsen J. In: Robertson T, editor. International Handbook of Participatory Design. Abingdon, England, UK: Routledge; 2013.

86. Jessen S, Mirkovic J, Ruland CM. Creating gameful design in mhealth: a participatory co-design approach. JMIR Mhealth Uhealth 2018 Dec 14;6(12):e11579 [FREE Full text] [doi: 10.2196/11579] [Medline: 30552080] 
87. Ledel Solem IK, Varsi C, Eide H, Kristjansdottir OB, Børøsund E, Schreurs KM, et al. A user-centered approach to an evidence-based electronic health pain management intervention for people with chronic pain: design and development of epio. J Med Internet Res 2020 Jan 21;22(1):e15889 [FREE Full text] [doi: 10.2196/15889] [Medline: $\underline{31961331]}$

88. Spook JE, Paulussen T, Paulissen R, Visschedijk G, Kok G, van Empelen P. Design rationale behind the serious self-regulation game intervention 'balance it': overweight prevention among secondary vocational education students in the Netherlands. Games Health J 2015 Oct;4(5):387-400. [doi: 10.1089/g4h.2014.0142] [Medline: 26181575]

89. Sardi L, Idri A, Fernández-Alemán JL. A systematic review of gamification in e-Health. J Biomed Inform 2017 Jul;71:31-48 [FREE Full text] [doi: 10.1016/j.jbi.2017.05.011] [Medline: 28536062]

90. DeSmet A, van Ryckeghem D, Compernolle S, Baranowski T, Thompson D, Crombez G, et al. A meta-analysis of serious digital games for healthy lifestyle promotion. Prev Med 2014 Dec;69:95-107 [FREE Full text] [doi:

10.1016/j.ypmed.2014.08.026] [Medline: 25172024]

91. Casanova P. Agile Processes: A Unifying Approach for the Future of Projects. In: PMI Global Congress Proceedings. 2013 Presented at: PGC'13; April 24, 2013; Istanbul, Turkey URL: https://www.researchgate.net/publication/ 273683645 Agile Processes A Unifying Approach for the Future of Projects

92. Braun V, Clarke V. Using thematic analysis in psychology. Qual Res Psychol 2006 Jan;3(2):77-101. [doi: 10.1191/1478088706qp063oa]

93. Carter N, Bryant-Lukosius D, DiCenso A, Blythe J, Neville AJ. The use of triangulation in qualitative research. Oncol Nurs Forum 2014 Sep;41(5):545-547. [doi: 10.1188/14.ONF.545-547] [Medline: 25158659]

94. XMind - Mind Mapping Software.: XMind URL: http://www.xmind.net [accessed 2020-10-23]

95. Huber M, van Vliet M, Giezenberg M, Winkens B, Heerkens Y, Dagnelie PC, et al. Towards a 'patient-centred' operationalisation of the new dynamic concept of health: a mixed methods study. BMJ Open 2016 Jan 12;6(1):e010091. [doi: 10.1136/bmjopen-2015-010091] [Medline: 26758267]

96. Maslow A. Motivation and Personality. Manhattan, New York, USA: Harper; 1954.

97. Maslow AH. Motivation and personality. In: Frager R, Fadiman J, McReynolds C, editors. Harper and Row. London, England: Longman; 1987.

98. Huber M, Knottnerus JA, Green L, van der Horst H, Jadad AR, Kromhout D, et al. How should we define health? Br Med J 2011 Jul 26;343:d4163. [doi: 10.1136/bmj.d4163] [Medline: 21791490]

99. Maslow A. Theory of human motivation. Psychol Rev 1943;50:370-396.

100. Deckers L. Motivation: Biological, Psychological, and Environmental. New York, USA: Routledge; 2018.

101. Parcel G, Kok G, Gottlieb NH. Planning Health Promoting Programs, an Intervention Mapping Approach. Second Edition. San Francisco, USA: Jossey-Bass (Wiley); 2011.

102. Gollwitzer P, Sheeran P. Implementation intentions and goal achievement: a meta - analysis of effects and processes. Adv Exper Soc Psychol 2006;38:69-119. [doi: 10.1016/S0065-2601(06)38002-1]

103. Ryan RM, Deci EL. Self-determination theory and the facilitation of intrinsic motivation, social development, and well-being. Am Psychol 2000;55(1):68-78. [doi: 10.1037/0003-066x.55.1.68]

104. Bandura A. Social Foundations of Thought and Action: A Social Cognitive Theory. 1st Edition. New Jersey, US: Prentice-Hall Inc; 1986.

105. Deci E, Ryan R. Intrinsic Motivation and Self-Determination in Human Behavior. New York, USA: Springer; 1985.

106. Sutin AR, Ferrucci L, Zonderman AB, Terracciano A. Personality and obesity across the adult life span. J Pers Soc Psychol 2011 Sep;101(3):579-592 [FREE Full text] [doi: 10.1037/a0024286] [Medline: 21744974]

107. Teixeira PJ, Marques MM. Health behavior change for obesity management. Obes Facts 2017;10(6):666-673 [FREE Full text] [doi: 10.1159/000484933] [Medline: 29237167]

108. Silva MN, Markland D, Minderico CS, Vieira PN, Castro MM, Coutinho SR, et al. A randomized controlled trial to evaluate self-determination theory for exercise adherence and weight control: rationale and intervention description. BMC Public Health 2008 Jul 9;8:234 [FREE Full text] [doi: 10.1186/1471-2458-8-234] [Medline: 18613959]

109. Stubbs RJ, Lavin JH. The challenges of implementing behaviour changes that lead to sustained weight management. Nutr Bull 2013 Feb 7;38(1):5-22. [doi: 10.1111/nbu.12002]

110. Dombrowski SU, Sniehotta FF, Avenell A, Johnston M, MacLennan G, Araújo-Soares V. Identifying active ingredients in complex behavioural interventions for obese adults with obesity-related co-morbidities or additional risk factors for co-morbidities: a systematic review. Health Psychol Rev 2012 Mar;6(1):7-32. [doi: 10.1080/17437199.2010.513298]

111. Dombrowski SU, Knittle K, Avenell A, Araújo-Soares V, Sniehotta FF. Long term maintenance of weight loss with non-surgical interventions in obese adults: systematic review and meta-analyses of randomised controlled trials. Be Med J 2014 May 14;348:g2646. [doi: 10.1136/bmj.g2646] [Medline: 25134100 ]

112. Butryn ML, Webb V, Wadden TA. Behavioral treatment of obesity. Psychiatr Clin North Am 2011 Dec;34(4):841-859 [FREE Full text] [doi: 10.1016/j.psc.2011.08.006] [Medline: 22098808]

113. Michie S, Abraham C, Whittington C, McAteer J, Gupta S. Effective techniques in healthy eating and physical activity interventions: a meta-regression. Health Psychol 2009 Nov;28(6):690-701. [doi: 10.1037/a0016136] [Medline: 19916637]

114. Sniehotta FF, Schwarzer R, Scholz U, Schüz B. Action planning and coping planning for long-term lifestyle change: theory and assessment. Eur J Soc Psychol 2005 Jul;35(4):565-576. [doi: 10.1002/ejsp.258] 
115. Swift DL, Johannsen NM, Lavie CJ, Earnest CP, Church TS. The role of exercise and physical activity in weight loss and maintenance. Prog Cardiovasc Dis 2014;56(4):441-447 [FREE Full text] [doi: 10.1016/j.pcad.2013.09.012] [Medline: 24438736]

116. Catenacci VA, Wyatt HR. The role of physical activity in producing and maintaining weight loss. Nat Clin Pract Endocrinol Metab 2007 Jul;3(7):518-529 [FREE Full text] [doi: 10.1038/ncpendmet0554] [Medline: 17581621]

117. Gardner B. A review and analysis of the use of 'habit' in understanding, predicting and influencing health-related behaviour. Health Psychol Rev 2015;9(3):277-295 [FREE Full text] [doi: 10.1080/17437199.2013.876238] [Medline: 25207647]

118. Gardner B, Lally P, Wardle J. Making health habitual: the psychology of 'habit-formation' and general practice. Br J Gen Pract 2012 Dec;62(605):664-666. [doi: 10.3399/bjgp12X659466] [Medline: 23211256]

119. van der Weiden A, Benjamins J, Gillebaart M, Ybema JF, de Ridder D. How to form good habits? A longitudinal field study on the role of self-control in habit formation. Front Psychol 2020;11:560 [FREE Full text] [doi: 10.3389/fpsyg.2020.00560] [Medline: 32292376]

120. Cleo G, Beller E, Glasziou P, Isenring E, Thomas R. Efficacy of habit-based weight loss interventions: a systematic review and meta-analysis. J Behav Med 2020 Aug;43(4):519-532. [doi: 10.1007/s10865-019-00100-w] [Medline: $\underline{31529279]}$

121. Lally P, van Jaarsveld CH, Potts HW, Wardle J. How are habits formed: modelling habit formation in the real world. Eur J Soc Psychol 2009 Jul 16;40(6):998-1009. [doi: 10.1002/ejsp.674]

122. Kelders SM, Oinas-Kukkonen H, Oörni A, van Gemert-Pijnen JE. Editorial: special issue on health behavior change support systems. Int J Med Inform 2016 Dec;96:1-2. [doi: 10.1016/j.ijmedinf.2016.07.001] [Medline: 27401468]

123. Niedderer K, Clune S, Ludden G. Design for Behaviour Change: Theories and practices of designing for change, 1 st Edition. England, UK: Routledge; 2017.

124. Bergeson SC, Dean JD. A systems approach to patient-centered care. J Am Med Assoc 2006 Dec 20;296(23):2848-2851. [doi: 10.1001/jama.296.23.2848] [Medline: 17179462]

125. Teixeira PJ, Silva MN, Mata J, Palmeira AL, Markland D. Motivation, self-determination, and long-term weight control. Int J Behav Nutr Phys Act 2012 Mar 2;9:22 [FREE Full text] [doi: 10.1186/1479-5868-9-22] [Medline: 22385818]

126. Poulimeneas D, Yannakoulia M, Anastasiou C, Scarmeas N. Weight loss maintenance: have we missed the brain? Brain Sci 2018 Sep 11;8(9):174 [FREE Full text] [doi: 10.3390/brainsci8090174] [Medline: 30208568 ]

127. Phelan S, Halfman T, Pinto AM, Foster GD. Behavioral and psychological strategies of long-term weight loss maintainers in a widely available weight management program. Obesity (Silver Spring) 2020 Feb;28(2):421-428 [FREE Full text] [doi: 10.1002/oby.22685] [Medline: 31970912]

128. Reyes NR, Oliver TL, Klotz AA, Lagrotte CA, Vander Veur SS, Virus A, et al. Similarities and differences between weight loss maintainers and regainers: a qualitative analysis. J Acad Nutr Diet 2012 Apr;112(4):499-505. [doi: 10.1016/j.jand.2011.11.014] [Medline: 22709701]

129. Ouellette JA, Wood W. Habit and intention in everyday life: the multiple processes by which past behavior predicts future behavior. Psychol Bull 1998 Jul;124(1):54-74. [doi: 10.1037/0033-2909.124.1.54]

130. Hollands GJ, Marteau TM, Fletcher PC. Non-conscious processes in changing health-related behaviour: a conceptual analysis and framework. Health Psychol Rev 2016 Dec;10(4):381-394 [FREE Full text] [doi: 10.1080/17437199.2015.1138093] [Medline: 26745243]

131. Verplanken B, Sui J. Habit and identity: behavioral, cognitive, affective, and motivational facets of an integrated self. Front Psychol 2019;10:1504 [FREE Full text] [doi: 10.3389/fpsyg.2019.01504] [Medline: 31354563]

132. Elfhag K, Rössner S. Who succeeds in maintaining weight loss? A conceptual review of factors associated with weight loss maintenance and weight regain. Obes Rev 2005 Feb;6(1):67-85. [doi: 10.1111/j.1467-789X.2005.00170.x] [Medline: 15655039]

133. Hooglugt F, Ludden GD. A mobile app adopting an identity focus to promote physical activity (MoveDaily): iterative design study. JMIR Mhealth Uhealth 2020 Jun 15;8(6):e16720 [FREE Full text] [doi: 10.2196/16720] [Medline: 32538795]

134. Kearney MH, O'Sullivan J. Identity shifts as turning points in health behavior change. West J Nurs Res 2003 Mar;25(2):134-152. [doi: 10.1177/0193945902250032] [Medline: 12666640]

135. Gardner B, de Bruijn G, Lally P. A systematic review and meta-analysis of applications of the Self-Report Habit Index to nutrition and physical activity behaviours. Ann Behav Med 2011 Oct;42(2):174-187. [doi: 10.1007/s12160-011-9282-0] [Medline: 21626256]

136. Silva MN, Vieira PN, Coutinho SR, Minderico CS, Matos MG, Sardinha LB, et al. Using self-determination theory to promote physical activity and weight control: a randomized controlled trial in women. J Behav Med 2010 Apr;33(2):110-122. [doi: 10.1007/s10865-009-9239-y] [Medline: 20012179]

137. Teixeira PJ, Carraça EV, Marques MM, Rutter H, Oppert J, de Bourdeaudhuij I, et al. Successful behavior change in obesity interventions in adults: a systematic review of self-regulation mediators. BMC Med 2015 Apr 16;13:84 [FREE Full text] [doi: 10.1186/s12916-015-0323-6] [Medline: 25907778]

138. Varkevisser RD, van Stralen MM, Kroeze W, Ket JC, Steenhuis IH. Determinants of weight loss maintenance: a systematic review. Obes Rev 2019 Feb;20(2):171-211 [FREE Full text] [doi: 10.1111/obr.12772] [Medline: $\underline{30324651]}$ 
139. IJsselsteijn W, de Kort Y, Midden C, Eggen B, van den Hoven E. Persuasive Technology for Human Well-Being: Setting the Scene. In: Lecture Notes in Computer Science. 2006 Presented at: PERSUASIVE'06; May 18-19, 2006; Springer, Berlin, Heidelberg.

140. Børøsund E, Ehlers SL, Varsi C, Clark MM, Andrykowski MA, Cvancarova M, et al. Results from a randomized controlled trial testing StressProffen; an application-based stress-management intervention for cancer survivors. Cancer Med 2020 Jun;9(11):3775-3785 [FREE Full text] [doi: 10.1002/cam4.3000] [Medline: 32243717]

141. Niedderer K, Clune S, Ludden G. Design for Behaviour Change for Health and Wellbeing. London, UK: Routledge, Taylor and Francis; 2017.

142. van Velsen L, Broekhuis M, Jansen-Kosterink S, Op den Akker H. Tailoring persuasive electronic health strategies for older adults on the basis of personal motivation: web-based survey study. J Med Internet Res 2019 Sep 6;21(9):11759 [FREE Full text] [doi: 10.2196/11759] [Medline: $\underline{\text { 31493323] }}$

143. Webb TL, Joseph J, Yardley L, Michie S. Using the internet to promote health behavior change: a systematic review and meta-analysis of the impact of theoretical basis, use of behavior change techniques, and mode of delivery on efficacy. $\mathrm{J}$ Med Internet Res 2010 Feb 17;12(1):e4 [FREE Full text] [doi: 10.2196/jmir.1376] [Medline: 20164043]

144. Chen J, Cade JE, Allman-Farinelli M. The most popular smartphone apps for weight loss: a quality assessment. JMIR Mhealth Uhealth 2015 Dec 16;3(4):e104 [FREE Full text] [doi: 10.2196/mhealth.4334] [Medline: 26678569]

145. Prochaska JJ, Nigg CR, Spring B, Velicer WF, Prochaska JO. The benefits and challenges of multiple health behavior change in research and in practice. Prev Med 2010;50(1-2):26-29 [FREE Full text] [doi: 10.1016/j.ypmed.2009.11.009] [Medline: 19948184]

146. Fuglestad PT, Rothman AJ, Jeffery RW, Sherwood NE. Regulatory focus, proximity to goal weight, and weight loss maintenance. Am J Health Behav 2015 Sep;39(5):709-720 [FREE Full text] [doi: 10.5993/AJHB.39.5.12] [Medline: 26248180]

147. Kelders SM, van Zyl LE, Ludden GD. The concept and components of engagement in different domains applied to ehealth: a systematic scoping review. Front Psychol 2020;11:926 [FREE Full text] [doi: 10.3389/fpsyg.2020.00926] [Medline: 32536888]

148. Vosbergen S, Mulder-Wiggers J, Lacroix J, Kemps H, Kraaijenhagen R, Jaspers M, et al. Using personas to tailor educational messages to the preferences of coronary heart disease patients. J Biomed Inform 2015 Feb;53:100-112 [FREE Full text] [doi: 10.1016/j.jbi.2014.09.004] [Medline: 25239261]

149. Dam RF, Siang TY. Personas - A Simple Introduction. Interaction Design Foundation. URL: http://www. interaction-design.org/literature/article/personas-why-and-how-you-should-use-them [accessed 2020-09-07]

150. Osterwalder A, Pigneur Y. Business Model Generation: A Handbook for Visionaries, Game Changers, and Challengers. Hoboken, New Jersey: John Wiley and Sons; 2014.

151. Ries E. The Lean Startup: How Today's Entrepreneurs Use Continuous Innovation to Create Radically Successful Businesses. Australia: Currency; 2011.

152. Osterwalder A, Pigneur Y, Bernarda G, Smith A, Papadakos T. Value Proposition Design: How to Create Products and Services Customers Want. Hoboken, New Jersey: Wiley; Oct 2014.

153. Mirkovic J, Jessen S, Kristjansdottir OB, Krogseth T, Koricho AT, Ruland CM. Developing technology to mobilize personal strengths in people with chronic illness: positive codesign approach. JMIR Form Res 2018 Jun 5;2(1):e10774 [FREE Full text] [doi: 10.2196/10774] [Medline: 30684404]

154. Catwell L, Sheikh A. Evaluating eHealth interventions: the need for continuous systemic evaluation. PLoS Med 2009 Aug;6(8):e1000126 [FREE Full text] [doi: 10.1371/journal.pmed.1000126] [Medline: 19688038]

155. Yardley L, Choudhury T, Patrick K, Michie S. Current issues and future directions for research into digital behavior change interventions. Am J Prev Med 2016 Nov;51(5):814-815. [doi: 10.1016/j.amepre.2016.07.019] [Medline: 27745680]

156. Petermans A, Cain R, editors. Design for Wellbeing. An Applied Approach. England, UK: Routledge; 2020.

157. Kip H, Sieverink F, van Gemert-Pijnen LJ, Bouman YH, Kelders SM. Integrating people, context, and technology in the implementation of a web-based intervention in forensic mental health care: mixed-methods study. J Med Internet Res 2020 May 26;22(5):e16906 [FREE Full text] [doi: 10.2196/16906] [Medline: 32348285]

158. Everett MR. Diffusion of Innovations. New York, USA: Free Press; 2003.

159. Sieverink F, Kelders S, Poel M, van Gemert-Pijnen L. Opening the black box of electronic health: collecting, analyzing, and interpreting log data. JMIR Res Protoc 2017 Aug 7;6(8):e156 [FREE Full text] [doi: 10.2196/resprot.6452] [Medline: $\underline{28784592]}$

\section{Abbreviations}

BCT: behavior change technique

CeHRes roadmap: Center for eHealth Research and Disease Management roadmap

OUH: Oslo University Hospital

PSD: persuasive system design

SH: Sørlandet Hospital 
VHT: Vestfold Hospital Trust

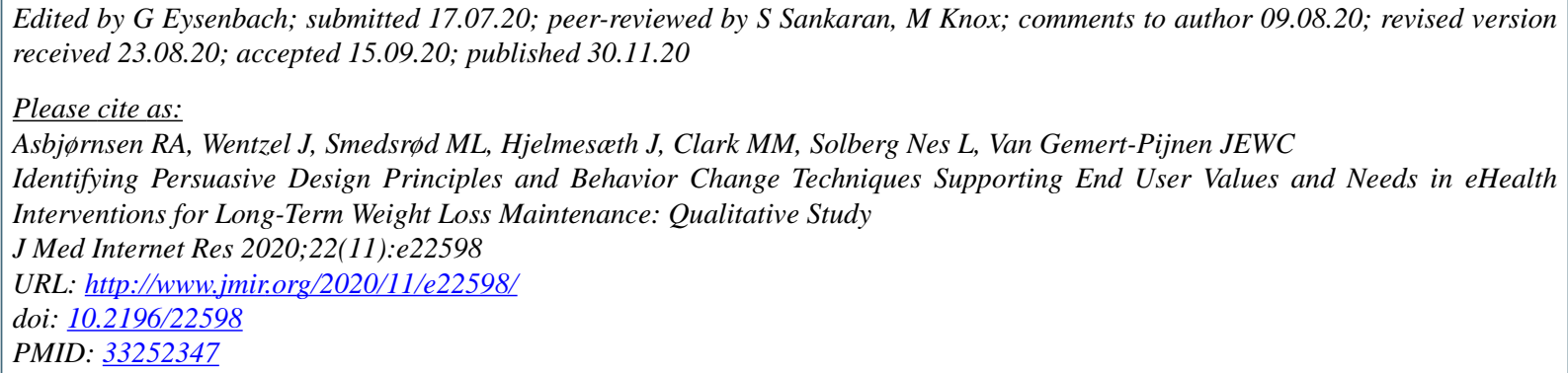

CRikke Aune Asbjørnsen, Jobke Wentzel, Mirjam Lien Smedsrød, Jøran Hjelmesæth, Matthew M Clark, Lise Solberg Nes, Julia E W C Van Gemert-Pijnen. Originally published in the Journal of Medical Internet Research (http://www.jmir.org), 30.11.2020. This is an open-access article distributed under the terms of the Creative Commons Attribution License (https://creativecommons.org/licenses/by/4.0/), which permits unrestricted use, distribution, and reproduction in any medium, provided the original work, first published in the Journal of Medical Internet Research, is properly cited. The complete bibliographic information, a link to the original publication on http://www.jmir.org/, as well as this copyright and license information must be included. 